\title{
Study on Molecular Immunity Mechanism of Porcine Rotavirus VP6 Proteins expressed in Lactobacillus plantarum NC8
}

SERIA SHONYELA ( $\sim$ seria.masole@sacids.org )

Sokoine University of Agriculture https://orcid.org/0000-0002-3347-2309

Wentao Yang

Jilin Agricultural University

Guilian Yang

Jilin Agricultural University

Chunfeng Wang

Jilin Agricultural University

\section{Research}

Keywords: Porcine Rotavirus, VP6, Lactobacillus plantarum NC8, immunogenicity, Pigs

Posted Date: January 7th, 2020

DOI: https://doi.org/10.21203/rs.2.20130/v2

License: (c) (i) This work is licensed under a Creative Commons Attribution 4.0 International License. Read Full License 


\section{Abstract}

Rotaviruses are the main cause of animal and infant diarrhea and are widely distributed worldwide. In the pig industry, porcine rotavirus infection is a significant cause of mortality and morbidity; therefore, the optimization and well-organized distribution of vaccines for infection prevention is needed. The molecularimmunological mechanisms of recombinant Lactobacillus plantarum NC8-pSIP409-pgsA-VP6Dcpep, NC8-pSIP409-pgsA-VP7-Dcpep and NC8-pSIP409-pgsA-VP6-VP7-Dcpep strains against porcine rotavirus were explored. At $12 \mathrm{~h}$ after the co-incubation of L. plantarum expressing rotavirus proteins with BMDCs, the effects of the strains on the differentiation of BMDCs were detected by FCM. The results showed that the recombinant strains could significantly promote the activation of BMDCs. The expression of cytokines in the above cells supernatants were detected by ELISA and the results suggested that the recombinant strains could significantly increase the production of IL-12P70 and inhibit the secretion of IL-6. CD $4+$ and CD8 + T cells from the spleen of non-immunized mice were sorted and cultured with the above activated BMDCs for $48 \mathrm{~h}$, and the expressions of IFN- $\gamma+$ and perforin in the cells and the contents of IFN-y in the supernatants were determined by FCM and ELISA, respectively. The results showed that the recombinant strains increased the expression of IFN- $\gamma+(4.33 \%)$ ofCD $4+\mathrm{T}$ cells and IFN- $\gamma+(7.68 \%)$ and perforin $(17.50 \%)$ of CD8 + T cells, as well as the secretion of cytokines IFN- - . The expression of IFN- $\gamma+(P<0.001)$ and perforin $(P<0.001)$ from VP6/VP7-specific CD8 $+T$ cells of spleen and MLN were detected in vivo and the recombinant groups were significantly increased. Moreover, the recombinant groups significantly promoted the proliferation of $\mathrm{T}$ cells in the spleen $(P<0.001)$. Our results confirmed that recombinant recombinant $L$. plantarum strains can effectively induce cellular immune response.

\section{Introduction}

Rotaviruses are members of the family Reoviridae. Depending on their particular inner capsid protein sequences, porcine rotaviruses are categorized into groups A, B and C [1]. Rotaviruses have a nonenveloped, double-stranded RNA genome that is composed of 11 segments enclosed by a triplelayered icosahedral capsid, [2-5]. The main source of acute diarrhea in piglets is porcine rotaviruses, which can cause high rates of mortality and morbidity [6-11]. In both pre- and post-weaning pigs, rotavirus Group A is the main source of rotavirus-associated diarrhea and accounts for $54 \%$ and $45 \%$ of the diarrhea experienced in those populations of pigs, respectively [1]. Some research has reported that in commercial pig farms, $89 \%$ of all rotavirus-associated diarrhea can be attributed to group A rotavirus infections [12]. Rotavirus outbreaks are difficult to prevent because they are transmitted via the fecal oral route and can survive in the environment for a long period of time. Replication of the virion takes place in the intestinal villi in epithelial cells and destroys enterocytes mainly in the ileum and jejunum, leading to villous atrophy [13-16]. In addition, in the affected regions, nutrients cannot be absorbed or digested, causing severe malabsorption [13-16]. The control of rotavirus infections requires a solid understanding of the epidemiology of rotaviruses, which will contribute to prevention programs and improve the current vaccines. Presently, the obtainable vaccines cannot provide adequate protection. To activate 
immunocompetence, repeated administrations and a large vaccine dose are generally needed. This repeatedly causes unwanted clinical signs. To overcome these weaknesses and deliver antigens to the mucosal immune system, possible improvements to lactic acid bacteria (LAB) have been proposed.

Mucosal immunity plays an important role in protective immunity because rotaviruses are enteric pathogens. In the gut, innate immune responses initiate acquired immune responses and offer the first line of protection against pathogenic microorganisms. In addition, the only appropriate way of eliciting gut immunity is to prompt the immune response via oral immunization because this oral route assists in gut-associated lymphoid tissue (GALT) stimulation, improving anti-viral IgA production $[17,18]$.

Lactobacillus is a food-grade bacterium. Lactobacillus plantarum (L. plantarum) is a common lactic acid bacterium and has a wide range of applications in industrial lactic acid fermentation and health care. Expression of a foreign antigen using a lactic acid bacteria strain induces mucosal (slgA) and systemic immune responses [19]. Lactic acid bacteria have the following advantages: (1) easy to culture, and some strains can construct a new expression vector system; (2) genetic manipulation method is simple, reproducible and efficient; (3) can guarantee genetic engineering products The relative safety of the foodgrade expression system for direct oral administration; (4) a highly regulatable promoter system capable of expressing toxin genes; (5) exogenous proteins can obtain good expression inside and outside the cell. (6) can effectively cause the body's immune response, and lasts for a long time; (7) lactic acid bacteria are safe, the expressed foreign protein can be taken directly together with the bacteria without purification. Therefore, it can be used as an ideal antigen presentation vector [20]. Live vaccines stimulate the most efficient defensive responses, unlike heat-killed or recombinant antigen formulations, because they elicit both mucosal and systemic immunity $[17,18]$. Repeated vaccinations and large vaccination doses are needed due to the challenges posed by oral vaccination, such as the fact that the gut environment habitually deactivates and/or denatures potential vaccinogens, causing fever and diarrhea, with the live vaccine often being shed in the feces $[17,18]$. With regard to the stimulation of mucosal immunity, lactic acid bacteria (LAB) can be used to overcome these challenges [21]. Furthermore, several $L A B$ strains are capable of colonizing and surviving the intestinal tract, stimulating nonspecific immunoadjuvant consequences [21]. It is essential to boost the immunogenicity of genetically engineered vaccines by combining them with suitable adjuvants because they are poorly immunogenic and composed of a single recombinant antigen. The dendritic cells play a central role in targeting peptide by directing innateand regulating adaptive/acquired immunity. Out of the three peptide pep3 later was renamed Dcpep, for the reason that Dcpep bound to both immature and mature DCs in a saturable way, than pep12 or pep18 and had the fascinating property to bind both human Monocyte-Derived Dendritic CellsmdDCs and mouse CD11C + I-A + DCs [22]

Herein, we constructed recombinant L. plantarum NC8 strains expressing porcine rotavirus VP6 to test the effectiveness of the expression of the VP6 porcine rotavirus protein by L. plantarum for oral vaccinations and the performance of L. plantarum as an antigen delivery system. Following the administration of live bacteria to mice, the immunogenic ability of these recombinant strains was analyzed. The oral administration of the recombinant strains NC8-pSIP409-pgsA-VP6-Dcpep, NC8-pSIP409-pgsA-VP7-Dcpep 
and NC8-pSIP409-pgsA-VP6-VP7-Dcpep stimulated specific anti-rotavirus systemic and mucosal immune responses. In mice immunized with L. plantarum NC8 expressing the VP6/VP7-Dcpep fusion, the effectiveness of the immune response evaluation was greater than in mice immunized with NC8pSIP409-pgsA, indicating the effectiveness of Dcpep as a mucosal adjuvant. Using standard molecular biology techniques, the recombinant NC8-pSIP409-pgsA-VP6-Dcpep, NC8-pSIP409-pgsA-VP7-Dcpep and NC8-pSIP409-pgsA-VP6-VP7-Dcpep was constructed to recognize DCs and the VP6-antigen more efficiently in the intestinal mucosa, and its immunogenicity was further investigated. The results indicated that the in vivo antibody levels were substantially improved after BALB/c mice were immunized by the lavage administration of our recombinant NC8-pSIP409-pgsA-VP6-Dcpep, NC8-pSIP409-pgsA-VP7Dcpep and NC8-pSIP409-pgsA-VP6-VP7-Dcpep

How the $T$ cell immune response in mice is induced to function in vitro and in vivo. The BMDCs activated by NC8-pSIP409-pgsA-VP6-Dcpep, NC8-pSIP409-pgsA-VP7-Dcpep and NC8-pSIP409-pgsA-VP6-VP7Dcpep were cultured in vitro with the primary $T$ cells sorted by magnetic beads to study the effects of in vitro antigens on DCs, T cells and intracellular cytokines, and sorting NC8-pSIP409-pgsA-VP6-Dcpep, NC8pSIP409-pgsA-VP7-Dcpep and NC8-pSIP409-pgsA-VP6-VP7-Dcpep by magnetic bead sorting. The CD8 + $T$ cells of the mice were used to explore the molecular immune mechanism of the mouse $T$ cell subsets in antiviral.

\section{Materials And Methods}

\section{Materials}

\section{Strain}

Four strains of lactic acid bacteria: NC8-pSIP409-pgsA', NC8-pSIP409-pgsA-VP6-Dcpep, NC8-pSIP409pgsA-VP7-Dcpep, NC8-pSIP409-pgsA-VP6-VP7-Dcpep.Experimental animalsFemale BALB/c mice of 5-6 weeks old SPF grade were purchased from Beijing Huakang Biotechnology Co., Ltd. ReagentsMouse CD 4 and CD8a magnetic bead sorting reagents (positive selection), mouse BD Fc blocking antibody, and purified anti-CD28 were purchased from BD Corporation of the United States. BD magnetic bead sorting buffer (0.5\% BSA, 2 mM EDTA and $0.09 \%$ sodium azide in PBS). The VP proteins of PRV was extracted and purified from T4-VP6 and T4-VP7 plasmid and stored at $-80^{\circ} \mathrm{C}$. Main experimental instrumentsThe sorted magnetic frame was purchased from BD, USA, and the other major experimental instruments are listed in Chapter 1.MethodEffect of co-expression of recombinant strains on BMDCs

The BMDCs of the mice were isolated as follows bilateral femur and tibia of mice was obtained aseptically. BMDCs of mice were isolated and cultured according to Ye et al. [23]. Immature BMDCs were collected on the eighth day of culture and the cells were counted by trypan blue staining. And planted in a 24-well cell culture plate, $2 \times 105$ cells per well (the medium contains FBS, no double antibody), and placed in a $37^{\circ} \mathrm{C}, 5 \% \mathrm{CO} 2$ incubator for cultivation. The $-80^{\circ} \mathrm{C}$ strains NC8-pSIP409-pgsA', NC8-pSIP409pgsA-VP6-Dcpep, NC8-pSIP409-pgsA-VP7-Dcpep, NC8-pSIP409-pgsA-VP6-VP7-Dcpep. were each streaked to a final concentration of On a $10 \mu \mathrm{g} / \mathrm{mLEm}$ MRS solid medium, a single colony was grown, and a single 
colony was picked up in $5 \mathrm{~mL}$ of MRS liquid medium at $30^{\circ} \mathrm{C}$ for anaerobic culture, transferred according to the previous method, and after SppIP was added to induce expression, the cells were collected. The pellet was washed twice with PBS, and finally suspended with PBS, and the concentration of the bacterial solution was adjusted to $2 \times 106 \mathrm{CFU} / 100 \mu \mathrm{L}$. The test was divided into 6 groups: empty cell (PBS) group, (409p') group, NC8-pSIP409-pgsA', NC8-pSIP409-pgsA-VP6-Dcpep, NC8-pSIP409pgsA-VP7-Dcpep, and NC8-pSIP409-pgsA-VP6-VP7-Dcpep group, each group of three duplicate wells. 100 $\mu \mathrm{L}$ of each group of strain was added to a paved 24-well cell culture plate, that is, $\mathrm{MOI}=10$. LPS was used as a positive control, $1 \mu \mathrm{L}$ (final concentration $1 \mu \mathrm{g} / \mathrm{mL}$ ) was added to each well; $1000 \mathrm{~g}$ was centrifuged for 10 min, cultured at $37^{\circ} \mathrm{C}, 5 \% \mathrm{CO} 2$ incubator for $3 \mathrm{~h}$, and gentamicin was added to each well at a final concentration of $4 \mu \mathrm{g} / \mathrm{mL}$ for $12 \mathrm{~h}$. The supernatant was collected and the expression of cytokines IL12 P70 and IL-6 in DCs was detected using an ELISA kit.The cells were carefully blown up with PBS, centrifuged at $1200 \mathrm{rpm}$ for $5 \mathrm{~min}$ at $4{ }^{\circ} \mathrm{C}$, washed twice with PBS, and $10 \mu \mathrm{L}$ of flow cytometry CD40, CD80, CD86 and CD83 were added to each tube, and incubated at room temperature for $20 \mathrm{~min}$ in the dark; The cells were washed twice with cold PBS, centrifuged at $4{ }^{\circ} \mathrm{C}, 2000 \mathrm{rpm}$ for $5 \mathrm{~min}$; the cell suspension was centrifuged for about $300 \mu \mathrm{L}$, and transferred to a flow tube. The effect of each group of recombinant strain on the activation and maturation of BMDCc was detected by flow cytometry.

Magnetic beads sorting spleen CD4+ $T$ cells and CD8+ $T$ cellsSterilizing the spleen cells of BALB/C aseptically according to the previous method, preparing a single cell suspension, and counting for use; Put the magnetic bead sorting buffer on the ice and use it now; $5 \mu \mathrm{L}$ of Fc blocking antibody was added in an amount of 107 spleen cells in $500 \mu \mathrm{L}$, and incubated on ice for $15 \mathrm{~min}$; Wash the cells with $1 \mathrm{~mL}$ magnetic beads sorting buffer, carefully mix; completely mix the mouse CD4/CD8 magnetic bead sorting reagent, add $50 \mu \mathrm{L}$ of sorting reagent to 107 splenocytes, mix thoroughly, and place at $4{ }^{\circ} \mathrm{C}$ for $30 \mathrm{~min}$; Immediately place the tube on the sorted magnetic stand and incubate for $10 \mathrm{~min}$ at room temperature; Carefully aspirate the supernatant, the supernatant contains negative fragments, remove the tube from the magnetic stand, add the same volume of buffer, gently suspend the cells, carefully blow; Put the tube on the magnetic stand again for sorting for 6 min; Repeat steps above, carefully discard the supernatant, add $500 \mu \mathrm{L}$ of 1640 complete medium to mix, which is the sorted cells; Dilute the sorted cells, count the cells on the hemocytometer, add the mouse flow antibody CD3e-PerCP-Cy5.5 and CD4-FITC to detect the content of CD4+ T cells and add the flow antibody CD3e. -PerCP-Cy5.5 and CD8-APC-Cy7 detect the content of $C D 8+T$ cells. Effect of activated BMDCs on $T$ cells The $C D 4+T$ cells and $C D 8+T$ cells of the mouse spleen were separately sorted according to the above method, and the concentration of the cells was adjusted to $2 \times 105 / 500 \mu \mathrm{L}$, and added to the 48-well cell culture plate; BMDCs of mice were stimulated with each group of recombinant strain, and the activated BMDCs $2 \times 105 /$ well were resuspended in $500 \mu \mathrm{L}$ of 1640 complete medium and added to the sorted CD4+T. The cells and CD8+ T cells were carefully mixed, placed in a $37^{\circ} \mathrm{C}, 5 \% \mathrm{CO} 2$ incubator for $48 \mathrm{~h}$, and the cell supernatant was collected, and the IFN- $y$ content in the cell supernatant was measured by ELISA; Cell pellet was carefully blown up with PBS, washed at $4{ }^{\circ} \mathrm{C} 2000 \mathrm{rpm} / 5 \mathrm{~min}, 1 \mathrm{~mL}$ PBS, and added to each well with 1640 complete medium to $500 \mu \mathrm{L}$; Add $2 \mu \mathrm{LPMA}$ per well, $5 \mu \mathrm{L}$ ionomycin, $1 \mu \mathrm{L}$ of blocking agent, and stimulate for $5 \mathrm{~h}$ in $37^{\circ} \mathrm{C} 5 \% \mathrm{CO} 2$ incubator; Collect the cells (the cells in the wells are first blown and then sucked) in 
a $1.5 \mathrm{~mL}$ centrifuge tube, at $4^{\circ} \mathrm{C} 2000 \mathrm{rpm} / 5 \mathrm{~min}$, discard the supernatant; Wash once with $1 \mathrm{~mL}$ PBS, $4^{\circ} \mathrm{C} 2000 \mathrm{rpm} / 5 \mathrm{~min}$, discard the supernatant; $100 \mu \mathrm{L}$ of PBS was suspended, CD4+ T cells were involved in the addition of CD3e and CD4 flow-through antibodies, CD8+ T cells were involved in the addition of CD3e and CD8 flow-through antibodies, and protected from light for 30 min at room temperature; Wash twice with PBS, discard the supernatant at $4{ }^{\circ} \mathrm{C} 2000 \mathrm{rpm} / 5 \mathrm{~min}$, add $250 \mu \mathrm{L}$ Fixation/permeabilization Solution, mix, and avoid light for $20 \mathrm{~min}$ at $4{ }^{\circ} \mathrm{C} ; 4^{\circ} \mathrm{C} 2000 \mathrm{rpm} / 5 \mathrm{~min}$, discard the supernatant, add $1 \mathrm{~mL}$ $1 \mathrm{X} \mathrm{BD}$ perm / wash buffer, $4^{\circ} \mathrm{C} 2000 \mathrm{rpm} / 5 \mathrm{~min}$, discard the supernatant, wash twice, and finally set the volume to $100 \mu \mathrm{L}$; Add $10 \mu \mathrm{L}$ of IFN- - -PE and CD107a-PE-Cy7 flow-through antibody to each tube (CD4+ T cells only participate in IFN-y-PE antibody), avoiding light for $30 \mathrm{~min}$ at $4{ }^{\circ} \mathrm{C} ; 1 \mathrm{~mL} 1 \mathrm{XBD}$ perm Wash once with / wash buffer, wash twice with PBS, dilute to $300 \mu \mathrm{L}$, pour into a flow tube, and test using flow cytometry.Grouping and immunization procedures for animal testingFemale BALB/c mice were randomly divided into six groups, followed by PBS group, 409p' group, NC8-pSIP409-pgsA', NC8-pSIP409-pgsA-VP6Dcpep, NC8-pSIP409-pgsA-VP7-Dcpep, and NC8-pSIP409-pgsA-VP6-VP7-Dcpep group, with 8 mice in each group, as shown in Table 1 below. Each mouse was administered with 109 CFU/100 $\mu \mathrm{L}$, and immunization was continued for 3 days at intervals of 14 days, followed by 3 consecutive days of booster immunization, and the following experiment was performed 7 days later.

Table. 1 Animal grouping and immune doses

\begin{tabular}{lll} 
Group & Immune dose & Number of mice \\
\hline PBS & $100 \mu \mathrm{L}$ & 8 \\
\hline $409 \mathrm{p}$ & $10^{9} \mathrm{CFU} / 100 \mu \mathrm{L}$ & 8 \\
\hline NC8-pSIP409-pgsA' & $10^{9} \mathrm{CFU} / 100 \mu \mathrm{L}$ & 8 \\
\hline NC8-pSIP409-pgsA-VP6-Dcpep & $10^{9} \mathrm{CFU} / 100 \mu \mathrm{L}$ & 8 \\
\hline NC8-pSIP409-pgsA-VP7-Dcpep & $10^{9} \mathrm{CFU} / 100 \mu \mathrm{L}$ & 8 \\
\hline NC8-pSIP409-pgsA-VP6-VP7-Dcpep & $10^{9} \mathrm{CFU} / 100 \mu \mathrm{L}$ & 8
\end{tabular}

Detection of VP-specific cytokinesAseptically obtain SPL and MLN from mice, prepare single-cell suspensions of SPL and MLN Spleen, MLN and P P knots were taken from the super-clean platform. 200 mesh steel mesh was placed in a $35 \mathrm{~mm}$ sterile dish, $1 \mathrm{~mL}$ of 1640 medium was added to the tissue and grinded. Cells were washed twice with 1640, and the supernatant was discarded. Spleen cells needed to lyse red blood cells with erythrocyte lysate, and then again. After washing, the cell suspension obtained through the membrane is the original solution. After dilution with PBS, the blood cell count plate is counted. use cell counting plates for cell counting, and adjust the concentration of cell suspension to 2 with 1640 complete medium. $\times 106 / 0.5 \mathrm{~mL}$; Add the adjusted cell suspension to a 48-well cell culture plate, add the purified VP protein at a final concentration of $20 \mu \mathrm{g} / \mathrm{mL}$, and place it in a $37^{\circ} \mathrm{C}, 5 \% \mathrm{CO} 2$ 
incubator for $8 \mathrm{~h}$, then add $1 \mu \mathrm{L}$ of resistance. Broken agent continued to culture for $4 \mathrm{~h}$; The cell culture plate was taken out, and the cells were collected by repeated pipetting into a $1.5 \mathrm{~mL}$ centrifuge tube, centrifuged at $4^{\circ} \mathrm{C}, 2000 \mathrm{rpm}$ for $5 \mathrm{~min}$, and the supernatant was discarded; The cells were suspended by adding $1 \mathrm{~mL}$ of pre-cooled PBS, centrifuged at $2000 \mathrm{rpm}$ for $5 \mathrm{~min}$ at $4{ }^{\circ} \mathrm{C}$, and the supernatant was discarded; Add $100 \mu \mathrm{L}$ of PBS, suspend the cells, and add $1 \mu \mathrm{L}$ of mouse CD3e, CD4 and CD8 flow antibodies, and avoid the light at room temperature for $30 \mathrm{~min}$; Washing with PBS, fixing and penetrating, finally adding IFN- $y$ and CD107a fluorescent antibodies for stain protection, washing with PBS, and finally suspending in $300 \mu \mathrm{L}$ of PBS, using flow cytometry. Effect on proliferation of T lymphocytesFor each sample of SPL and MLN, according to the above counting results, a part of the cell suspension was taken, and the concentration of the adjusted cells was $1 \times 107 \mathrm{cells} / \mathrm{mL}$; Washing the cells twice with PBS, removing residual serum, and suspending with PBS; Add the final concentration to $2 \mu \mathrm{M}$ CFSE and mix well. Incubate in a $37^{\circ} \mathrm{C}$ incubator for $10 \mathrm{~min}$ in the dark. Remove every $2 \mathrm{~min}$, invert one at a time, add 4 volumes of cold 1640 complete medium, mix well, ice. Incubate for 5 min to block the reaction; Centrifuge at $2000 \mathrm{rpm}$ for $5 \mathrm{~min}$ at $4{ }^{\circ} \mathrm{C}$, discard the supernatant, wash the cells twice with 1640 complete medium, and suspend in $1 \mathrm{~mL}$ of 1640 complete medium. The cells at this time are lymphocytes stained with CSFE; $5 \times 105$ cells were stained and added to 96 -well cell culture plates. Three replicate wells were made for each sample, and $20 \mu \mathrm{g} / \mathrm{mL}$ final concentration of VP protein and $2 \mu \mathrm{g} / \mathrm{mL}$ mouse anti-CD28 were added. The antibody was cultured in a $37^{\circ} \mathrm{C}, 5 \% \mathrm{CO} 2$ incubator for 3 days; After the completion of the culture, the cells were collected, washed twice with PBS, and then $10 \mu \mathrm{L}$ of anti-mouse flow antibodies CD4-PE and CD8-APC-Cy7 were simultaneously added, and incubated at $37^{\circ} \mathrm{C}$ for $30 \mathrm{~min}$ in the dark; The cells were washed twice with PBS, suspended in $300 \mu \mathrm{L}$ of PBS, transferred to a flow tube, and detected by flow cytometry.Statistical analysis of dataFlow cytometry was analyzed by Flowjo 7.6.1 software, GraphPad Prism 5 software was used for mapping and statistical data, and one-way ANOVA was used to calculate the difference between each group of data $(*, P<0.05 ; * \star, P<0.01 ; * \star \star, P<0.001)$.

\section{Results}

Effect of lactic acid bacteria expressing VP6 and VP7 on activation and maturation of BMDCs and secretion of cytokines

We used BMDCs as a cell model to stimulate BMDCs using lactic acid bacteria to detect the effects on DCs activation and maturation. The results showed that compared with the NC8-pSIP409-pgsA group, the NC8-pSIP409-pgsA-VP6-Dcpep, NC8-pSIP409-pgsA-VP7-Dcpep, and NC8-pSIP409-pgsA-VP6-VP7-Dcpep groups significantly and significantly increased the MFI of CD40 $(P<0.05), C D 80(P<0.001)$ and CD86 ( $P$ $<0.001$ ) in the DCs subpopulation, and promoted The differentiation of BMDCs is shown in (Figs. 1,2,and 3). For DCs subgroup CD83, the MFI of CD83 was significantly increased in the NC8-pSIP409-pgsA group compared with the 409p' group ( $\mathrm{P}<0.01$ ), and the NC8-pSIP409-pgsA-VP6-Dcpep, NC8-pSIP409-pgsAVP7-Dcpep, and NC8-pSIP409-pgsA-VP6-VP7-Dcpep groups were significantly elevated. High $(P<0.05)$, as shown in Fig. 4. The above results indicate that the lactic acid bacteria in the NC8-pSIP409-pgsA-VP6Dcpep, NC8-pSIP409-pgsA-VP7-Dcpep, and NC8-pSIP409-pgsA-VP6-VP7-Dcpep groups can significantly promote the differentiation of DCs. 
At the same time, we also used the ELISA kit to detect the effects of cytokines IL-12P70 and IL-6 secreted by DCs. The results showed that NC8-pSIP409-pgsA-VP6-Dcpep, NC8-pSIP409-pgsA-VP7-Dcpep, and NC8pSIP409-pgsA-VP6-VP7-Dcpep significantly increased the secretion of IL-12P70 compared with the NC8pSIP409-pgsA, group $(P<0.05)$; compared with the empty vector 409p' and NC8-pSIP409-pgsA-VP6Dcpep, groups, the IL group significantly decreased in the secretion of IL-6. $(P<0.05)$, the NC8-pSIP409pgsA-VP6-Dcpep, group decreased significantly $(P<0.001)$, and NC8-pSIP409-pgsA-VP6-Dcpep, group showed a decreasing trend compared with the NC8-pSIP409-pgsA-VP7-Dcpep, and NC8-pSIP409-pgsAVP6-VP7-Dcpep groups, but the difference was not significant, as shown in Fig. 5. The above results indicated that the NC8-pSIP409-pgsA-VP6-Dcpep, group significantly promoted the secretion of IL-12P70, inhibited the secretion of IL-6, and then promoted the differentiation of T cells into Th1 direction and inhibited the differentiation into Th2 direction.

\section{Effect of in vitro activated BMDCs on T cells}

In order to simulate the in vivo DCs to obtain antigen and then deliver it to T cells, the process of cellular immunity and humoral immunity is exerted. In vitro, we used magnetic bead sorting reagent to sort CD $4+$ and CD8 $+T$ cells from spleens of unimmunized BALB/c mice, and co-cultured with the above-mentioned groups of activated BMDCs for 48 hours to detect IFN- $\gamma$ in CD $4+T$ cells. And changes in IFN- $\gamma$ and perforin in CD8 $+\mathrm{T}$ cells, including detection of secreted cytokines. From the results, we can see that compared with the 409p' group, the expression of IFN- $y$ in CD $4+T$ cells was significantly increased in the HA group $(P<0.05)$, and the increase in the aCD11c-HA group was extremely significant $(P<0.01)$. As shown in Fig. 6, compared with the NC8-pSIP409-pgsA group, the NC8-pSIP409-pgsA-VP6-Dcpep, NC8pSIP409-pgsA-VP7-Dcpep, and NC8-pSIP409-pgsA-VP6-VP7-Dcpep groups group significantly increased the expression of IFN- $\gamma$ in CD8 $+T$ cells $(P<0.001)$, as shown in Fig. 7; the NC8-pSIP409-pgsA group group significantly increased CD8 $+T$ cells. CD107a $(P<0.01)$, the expression of perforin, was significantly increased in the NC8-pSIP409-pgsA-VP6-Dcpep, NC8-pSIP409-pgsA-VP7-Dcpep, and NC8pSIP409-pgsA-VP6-VP7-Dcpep groups compared with the two empty vector groups $(P<0.001)$, as shown in Fig. 8. The above results show that the NC8-pSIP409-pgsA-VP6-Dcpep, NC8-pSIP409-pgsA-VP7-Dcpep, and NC8-pSIP409-pgsA-VP6-VP7-Dcpep groups is superior to the NC8-pSIP409-pgsA group in exerting antiviral effects mainly on CD8 + T cells, and interferon and perforin play an important role.

Next, we evaluated the expression of IFN-y in the supernatant of activated BMDCs co-cultured with CD4 + and CD8 + T cells. The results are shown in Figs. 9 and 10, the NC8-pSIP409-pgsA-VP6-Dcpep, NC8pSIP409-pgsA-VP7-Dcpep, and NC8-pSIP409-pgsA-VP6-VP7-Dcpep groups and NC8-pSIP409-pgsA group, one empty vector groups. In comparison, the levels of IFN- $\gamma$ in CD4 + and CD $8+T$ cell supernatants were significantly increased $(P<0.001)$, and some of them polarized T cells in the direction of Th1, which was promoted by the cytokine IL-12P70 secreted by the above DCs. The results of T cells in the Th1 direction are consistent.

Effects on mouse SPL and MLN-specific T cells 
SPL and MLN of the mice after stimulation immunization were performed using the purified VP protein, and the reaction of specific T cells against the VP protein was detected. In SPL and MLN, compared with the 409p' group, the VP group significantly promoted the expression of CD $4+I F N-\gamma+T$ cells $(P<0.05, P<$ 0.01), and the expression of the NC8-pSIP409-pgsA-VP6-Dcpep, NC8-pSIP409-pgsA-VP7-Dcpep, and NC8pSIP409-pgsA-VP6-VP7-Dcpep groups group increased significantly $(\mathrm{P}<0.001)$. ), the NC8-pSIP409-pgsAVP6-Dcpep, NC8-pSIP409-pgsA-VP7-Dcpep, and NC8-pSIP409-pgsA-VP6-VP7-Dcpep groups has an increasing trend compared with the NC8-pSIP409-pgsA group, but the difference is not significant, as shown in Figs. 11 and 12; for CD 8 + IFN- $\gamma+$ T cells, as shown in Figs. 13 and 14, in the SPL, Compared with the two empty vector groups, the NC8-pSIP409-pgsA group were significantly increased $(P<0.05)$, and the NC8-pSIP409-pgsA-VP6-Dcpep, NC8-pSIP409-pgsA-VP7-Dcpep, and NC8-pSIP409-pgsA-VP6-VP7Dcpep groups were significantly increased $(P<0.01)$. In the MLN, the NC8-pSIP409-pgsA-VP6-Dcpep, NC8pSIP409-pgsA-VP7-Dcpep, and NC8-pSIP409-pgsA-VP6-VP7-Dcpep groups were significantly higher than the HA group $(P<0.05)$. <0.05); As shown in Figs. 15 and 16, for the CD8 $+C D 107 a+T$ cell response, the NC8-pSIP409-pgsA group was significantly increased in the SPL compared with the 409p' group $(\mathrm{P}<$ 0.01), the NC8-pSIP409-pgsA-VP6-Dcpep, NC8-pSIP409-pgsA-VP7-Dcpep, and NC8-pSIP409-pgsA-VP6VP7-Dcpep groups were significantly improved $(P<0.05)$. $<0.001)$, while in the MLN, the the NC8-pSIP409pgsA group increased significantly $(P<0.05)$, and the the NC8-pSIP409-pgsA-VP6-Dcpep, NC8-pSIP409pgsA-VP7-Dcpep, and NC8-pSIP409-pgsA-VP6-VP7-Dcpep groups increased significantly $(P<0.01)$. The above results indicate that both IFN-y and perforin in CD8 + T cells have antiviral effects, and the NC8pSIP409-pgsA-VP6-Dcpep, NC8-pSIP409-pgsA-VP7-Dcpep, and NC8-pSIP409-pgsA-VP6-VP7-Dcpep groups group is superior to the the NC8-pSIP409-pgsA, groups group mainly in IFN-y.

Effect on the proliferation of mouse SPL cells

The above results indicate that in the SPL and MLN of mice, the NC8-pSIP409-pgsA-VP6-VP7-Dcpep, group can significantly increase the changes of IFN-y and perforin in T cells. To further explore the effect on the proliferation of T cells, we used CFSE to label the spleen cells. FCM detects the proliferative capacity of CD $4+T$ cells and CD8 $+T$ cells in SPL. The results are shown in Figs. 17 and 18. Compared with the NC8-pSIP409-pgsA-VP6-Dcpep and NC8-pSIP409-pgsA-VP7-Dcpep groups, the NC8-pSIP409pgsA-VP6-VP7-Dcpep group significantly increased CD $4+T$ cells $(P<0.01)$ and significantly increased the proliferation of $C D 8+T$ cells $(P<0.05)$.

\section{Discussion}

To further explore the molecular immune mechanisms of NC8-pSIP409-pgsA-VP6-VP7-Dcpep

in antiviral infection, we used BMDCs to mimic the process by which in vivo antigens are captured by DCs and delivered to T cells to secrete cytokines. We found that NC8-pSIP409-pgsA-VP6-VP7-Dcpep lactic acid bacteria significantly promoted the activation of BMDCs compared to the NC8-pSIP409-pgsA-VP7-Dcpep strain. After antigen-activated DCs, DCs secrete specific cytokines such as IL-12P70, IL-6, TNF-a and IL-2. The increase of IL-12P70 indicates that T cells are polarized in the Th1 direction, and the increase of IL- 6 
indicates T cells polarize to Th2 and inhibit Th1-type responses. Therefore, we evaluated the expression of IL-12P70 and IL-6 in the supernatant of the cells after stimulation of BMDCs. The secretion of IL-12P70 in NC8-pSIP409-pgsA-VP6-VP7-Dcpep group increased and IL-6 decreased significantly, indicating that the NC8-pSIP409-pgsA-VP6-VP7-Dcpep, NC8-pSIP409-pgsA-VP6-Dcpep and NC8-pSIP409-pgsA-VP7Dcpep groups may promote $T$ cells to Th1. Type direction polarization.

To evaluate the effect of in vitro BMDCs on T cells after activation, we used magnetic bead sorting reagents to sort CD $4+$ and $C D 8+T$ cells from spleens of unimmunized mice. The sorted CD $4+$ and $C D 8$ $+T$ cells were co-cultured with the activated BMDCs for $48 \mathrm{~h}$, respectively. When the ratio of $\mathrm{T}$ cells to BMDCs was 1:1, the NC8-pSIP409-pgsA-VP6-VP7-Dcpep lactic acid bacteria were compared with the NC8pSIP409-pgsA-VP6-Dcpep and NC8-pSIP409-pgsA-VP7-Dcpep single expression strain, and the T cells were intracellular IFN. At this time, the content of IFN- $y$ in the cell supernatant was also significantly increased, which promoted the Th1-type reaction, which was consistent with the results of the abovementioned DCs secreting cytokines. In fact, regarding the ratio of T cells to BMDCs of 2:1, we also performed experiments on T cell intracellular factors and cytokines secreted in cell supernatants, at this time NC8-pSIP409-pgsA-VP6-VP7-Dcpep, NC8-pSIP409-pgsA-VP6-Dcpep and NC8-pSIP409-pgsA-VP7Dcpep lactic acid bacteria CD4 + and CD8 + T cells. The expression level of intracellular factors was increased, not very significant, and there was no significant difference in the amount of IFN- $y$ in the cell supernatant between three groups (data not shown). The above results may be due to the fact that the efficiency of DCs in the delivery of antigens is certain. When T cells increase, the overall efficiency of T cell population activation decreases, which leads to decreased expression of intracellular factors in CD4 + and CD8 + T cells, and corresponding secretion of cytokines.

We evaluated the ability of CD8 + T cells to release IFN- $\gamma$ and perforin by in vitro and in vivo experiments, and as a result, the NC8-pSIP409-pgsA-VP6-VP7-Dcpep, NC8-pSIP409-pgsA-VP6-Dcpep and NC8-pSIP409pgsA-VP7-Dcpep groups were significantly elevated, and at the same time, specific CD4 + T cells and CD8 $+T$ cells in the spleen proliferated in large amounts.

Yang Wentao et al [24] constructed recombinant lactic acid bacteria NC8-pSIP409-NP-M1-DCpep, sorted $\mathrm{CD} 4+T$ cells and $\mathrm{CD} 8+T$ cells of spleen after immunization, and CD $4+T$ cells, CD8 $+T$ cells and mixed $\mathrm{CD} 4+T$ cells and CD8 $+T$ cells were reinfused into NOD/Lt-SCID mice, and it was found that CD $8+T$ cells play an important role in the anti-avian influenza virus process. In our experiments, in vitro and in vivo experiments also showed that $\mathrm{CD} 8+\mathrm{T}$ cells play a key role.

\section{Conclusion}

Our results provide evidence to suggest that NC8-pSIP409-pgsA-VP6-VP7-Dcpep, NC8-pSIP409-pgsA-VP6Dcpep and NC8-pSIP409-pgsA-VP7-Dcpep strains may have a direct effect on the functional capacity of DC, modulating mucosal T cell responses and can activate BMDCs in vitro, promote the secretion of IL12 P70 by DCs, and then promote the polarization of T cells to Th1, and promote the expression of IFN- $\gamma$ and perforin in CD8+ T cells. NC8-pSIP409-pgsA-VP6-VP7-Dcpep, NC8-pSIP409-pgsA-VP6-Dcpep and 
NC8-pSIP409-pgsA-VP7-Dcpep strains significantly increased the expression of intracellular VP6 and VP7-specific cytokines IFN- $\gamma$ and perforin in CD8+ T cells of mouse spleen and MLN, and significantly promoted the proliferation of CD4+ T cells and CD8+ T cells in spleen.

\section{Declarations}

\section{Ethics approval and consent to participate:}

This study was carried out in agreement with the principles established by Jilin Agriculture University Changchun China and guide for the use of laboratory and care animals and all experimental protocols were approved by a Jilin Agriculture University (No. JLAU08201007).

Consent for publication: Not applicable

\section{Availability of data and materials: will be provided after acceptance}

Competing interests:

Author1 declares that she has no conflict of interest.

Author 2 declares that he has no conflict of interest.

Author 3 declares that she has no conflict of interest.

Author 4 declares that he has no conflict of interest

Funding: This work was supported by The National Key Research and Development Program of China (2017YFD0501000).

Authors' contributions

Author 1 SMS -searching data, wrote manuscript and acted as corresponding author

Author 2 WY -editing manuscript

Author $3 \mathrm{GY}$ - editing the manuscript and supervision of the manuscript

Author $4 \mathrm{CW}$ - editing the manuscript and supervision of the manuscript

\section{All authors have read and approved the manuscript}

\section{Acknowledgement:}

We are thankful to the Jilin Agricultural University for the internet to download Data for this study. 


\section{References}

1.

Kava R. Rotavirus Vaccines Do More Than Prevent Diarrhea. American Council on Science and Health 2018.

2.

Hull JJ, Marthaler D, Rossow S, Ng TFF, Montmayeur AM, Magana L, Moon S-S, Jiang B. Genomic Sequence of the First Porcine Rotavirus Group H Strain in the United States. Genome Announcements. 2016;4:e01763-01715.

3.

Marthaler D, Rossow K, Gramer M, Collins J, Goyal S, Tsunemitsu H, Kuga K, Suzuki T, Ciarlet M, Matthijnssens J. Detection of substantial porcine group B rotavirus genetic diversity in the United States, resulting in a modified classification proposal for G genotypes. Virology. 2012;433:85-96.

4.

Matthijnssens J, Ciarlet M, McDonald SM, Attoui H, Banyai K, Brister JR, Buesa J, Esona MD, Estes MK, Gentsch JR, et al. Uniformity of rotavirus strain nomenclature proposed by the Rotavirus Classification Working Group (RCWG). Arch Virol. 2011;156:1397-413.

5 .

Paul PS, Lyoo YS. Immunogens of rotaviruses. Vet Microbiol. 1993;37:299-317.

6.

Gachanja E, Buza J, Petrucka P. Prevalence of Group A Rotavirus in Piglets in a Peri-Urban Setting of Arusha, Tanzania. Journal of Biosciences Medicines. 2016;04:37-44.

7.

Wilhelm B, Waddell L, Greig J, Rajic A, Houde A, McEwen SA. A scoping review of the evidence for public health risks of three emerging potentially zoonotic viruses: hepatitis E virus, norovirus, and rotavirus. Prev Vet Med. 2015;119:61-79.

8.

Nataraju SM, Chattopadhyay UK, Krishnan T. A study on the possibility of zoonotic infection in rotaviral diarrhoea among calves and buffalo calves in and around Kolkata, India. Eur Rev Med Pharmacol Sci. 2009;13:7-11.

9.

Ambily R, Mini M, John K, Nair GK. First report of bovine rotavirus from Kerala. Biosci Biotechnol Res Asia. 2009;6:245-9.

10.

Manuja BK, Prasad M, Manuja A, Gulati BR, Prasad G. A novel genomic constellation (G10P[3]) of group A rotavirus detected from buffalo calves in northern India. Virus Res. 2008;138:36-42.

11.

Ghosh S, Samajdar S, Sinha M, Kobayashi N, Taniguchi K, Naik TN. Molecular characterization of rare bovine group A rotavirus G15P[11] and G15P[21] strains from eastern India: identification of simian SA11-like VP6 genes in G15P[21] strains. Virus Genes. 2008;37:241-9. 
12.

Vlasova AN, Amimo JO, Saif LJ. Porcine Rotaviruses: Epidemiology, Immune Responses and Control Strategies. 2017, 9:48.

13.

Dewey C, Carman S, Pasma T, Josephson G, McEwen B. Relationship between group A porcine rotavirus and management practices in swine herds in Ontario. The Canadian Veterinary Journal. 2003;44:649-53. 14.

Shaw AL, Rothnagel R, Zeng CQY, Lawton JA, Ramig RF, Estes MK, Prasad BVV. Rotavirus structure: interactions between the structural proteins. In: Chiba S, Estes MK, Nakata S, Calisher $\mathrm{CH}$, editors. Viral Gastroenteritis. Vienna: Springer Vienna; 1996. pp. 21-7.

15.

Chitambar SD, Arora R, Kolpe AB, Yadav MM, Raut CG. Molecular characterization of unusual bovine group A rotavirus G8P[14] strains identified in western India: Emergence of P[14] genotype. Vet Microbiol. 2011;148:384-8.

16.

Malik YS, Sharma K, Vaid N, Chakravarti S, Chandrashekar KM, Basera SS, Singh R, Minakshi, Prasad G, Gulati BR, et al. Frequency of group A rotavirus with mixed $\mathrm{G}$ and $\mathrm{P}$ genotypes in bovines: predominance of G3 genotype and its emergence in combination with G8/G10 types. J Vet Sci. 2012;13:271-8. 17.

Matson DO, O'Ryan ML, Herrera I, Pickering LK, Estes MK. Fecal antibody responses to symptomatic and asymptomatic rotavirus infections. J Infect Dis. 1993;167:577-83.

18.

Coulson BS, Grimwood K, Hudson IL, Barnes GL, Bishop RF. Role of coproantibody in clinical protection of children during reinfection with rotavirus. J Clin Microbiol. 1992;30:1678-84.

19.

Bermudez-Humaran LG, Kharrat P, Chatel JM, Langella P. Lactococci and lactobacilli as mucosal delivery vectors for therapeutic proteins and DNA vaccines. Microb Cell Fact. 2011;10(Suppl 1):4. 20.

Administration USFaD. Evaluating the safety of antimicrobial new animal drugs with regard to their microbiological effects on bacteria of human health concern. Food and Drug Administration - Guidance for Industry No 1522003.

21.

Pavan S, Hols P, Delcour J, Geoffroy MC, Grangette C, Kleerebezem M, Mercenier A. Adaptation of the nisin-controlled expression system in Lactobacillus plantarum: a tool to study in vivo biological effects. Appl Environ Microbiol. 2000;66:4427-32.

22.

Curiel TJ, Morris C, Brumlik M, Landry SJ, Finstad K, Nelson A, Joshi V, Hawkins C, Alarez X, Lackner A, Mohamadzadeh M. Peptides identified through phage display direct immunogenic antigen to dendritic cells. J Immunol. 2004;172:7425-31.

23. 
Ye L, Jiang Y, Yang G, Yang W, Hu J, Cui Y, Shi C, Liu J, Wang C. Murine bone marrow-derived DCs activated by porcine rotavirus stimulate the Th1 subtype response in vitro. Microb Pathog. 2017;110:325-34.

24.

Pol JM, Broekhuysen-Davies JM, Wagenaar F, La Bonnardiere C. The influence of porcine recombinant interferon-alpha 1 on pseudorabies virus infection of porcine nasal mucosa in vitro. J Gen Virol. 1991;72(Pt 4):933-8.

\section{Figures}
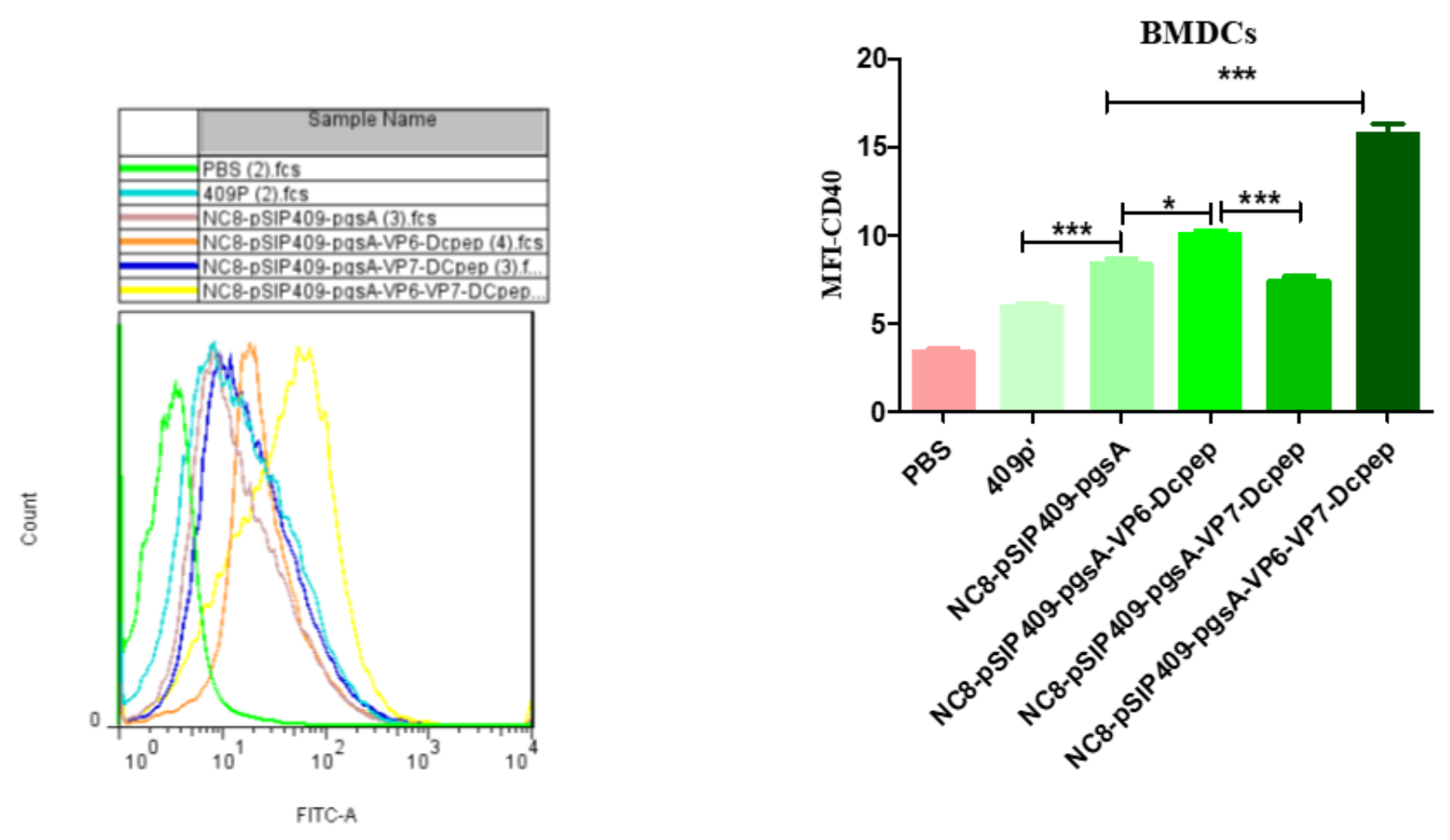

Figure 1

the effect on $\mathrm{CD} 40$ 

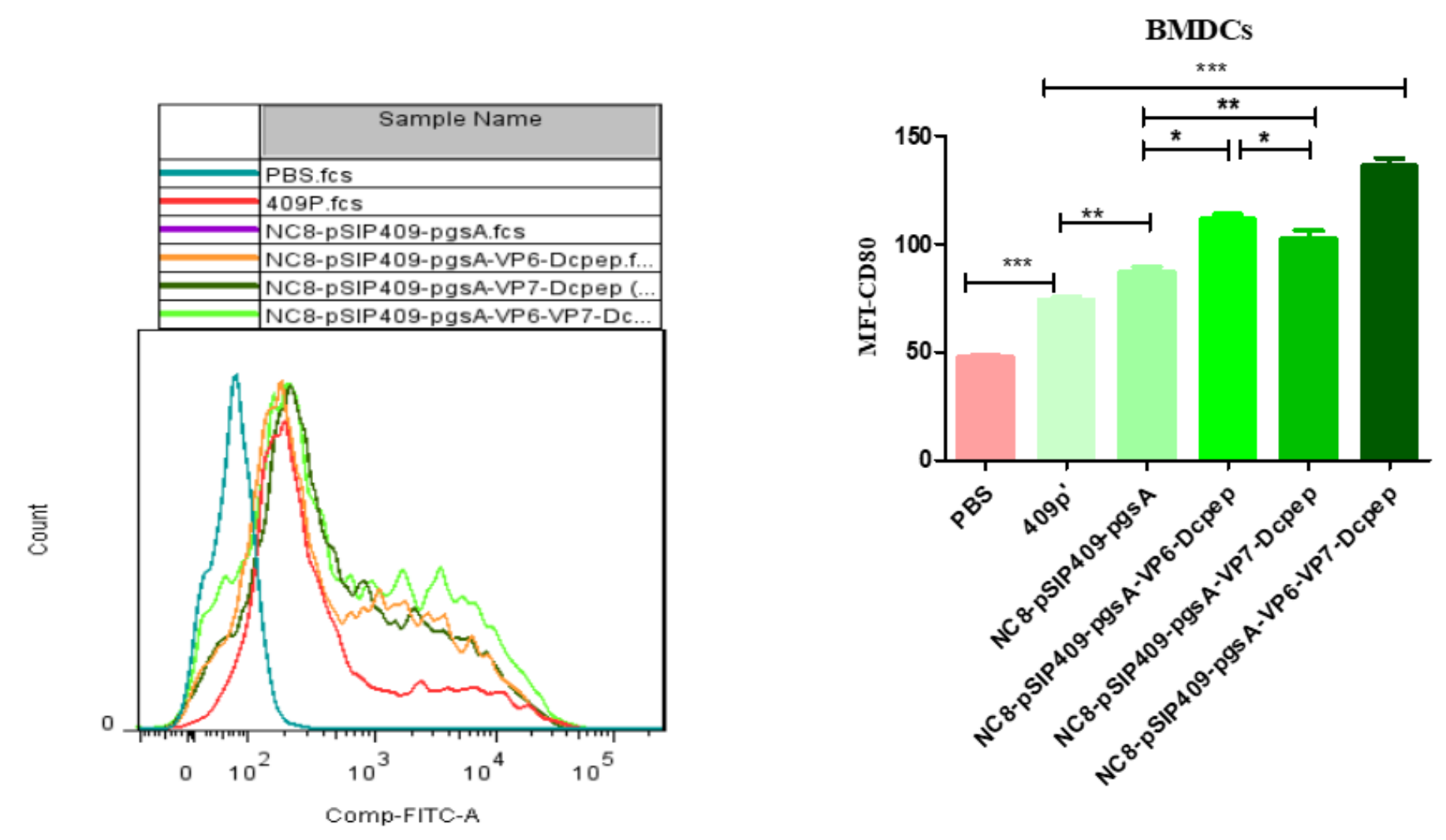

Figure 2

the effect on CD80 

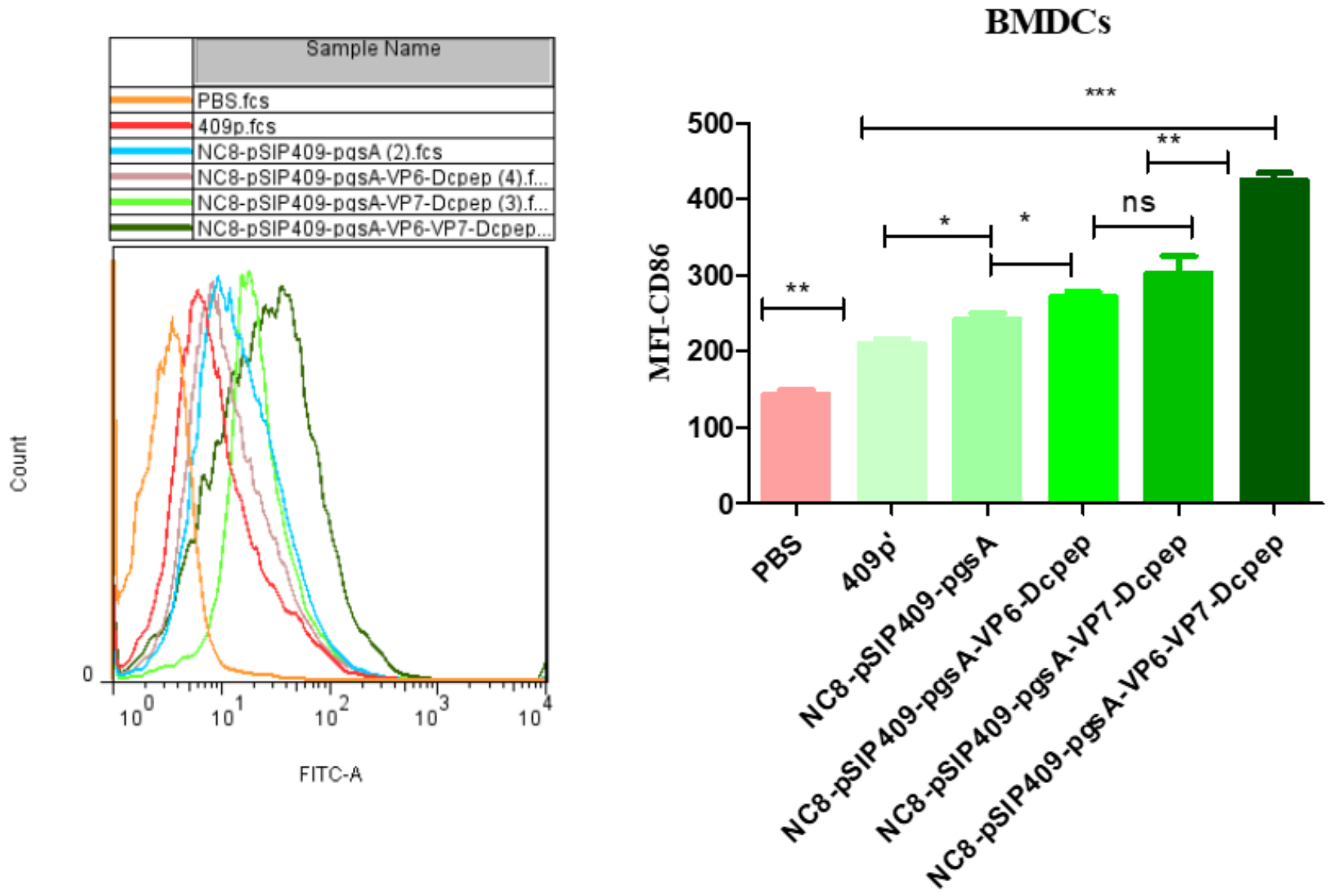

Figure 3

the effect on CD86 
BMDCs
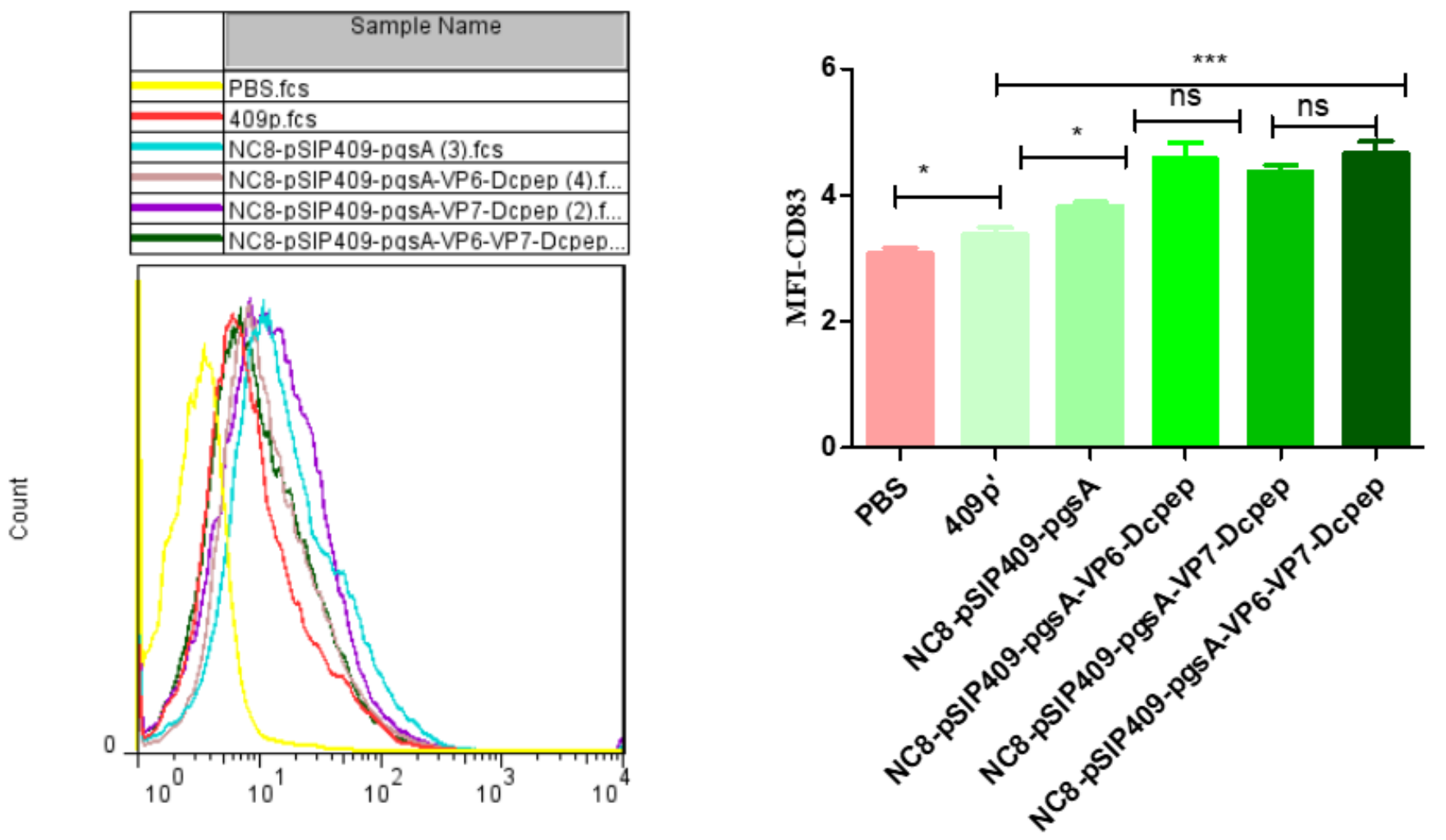

FITC-A

Figure 4

the effect on CD83 
IL-12P70

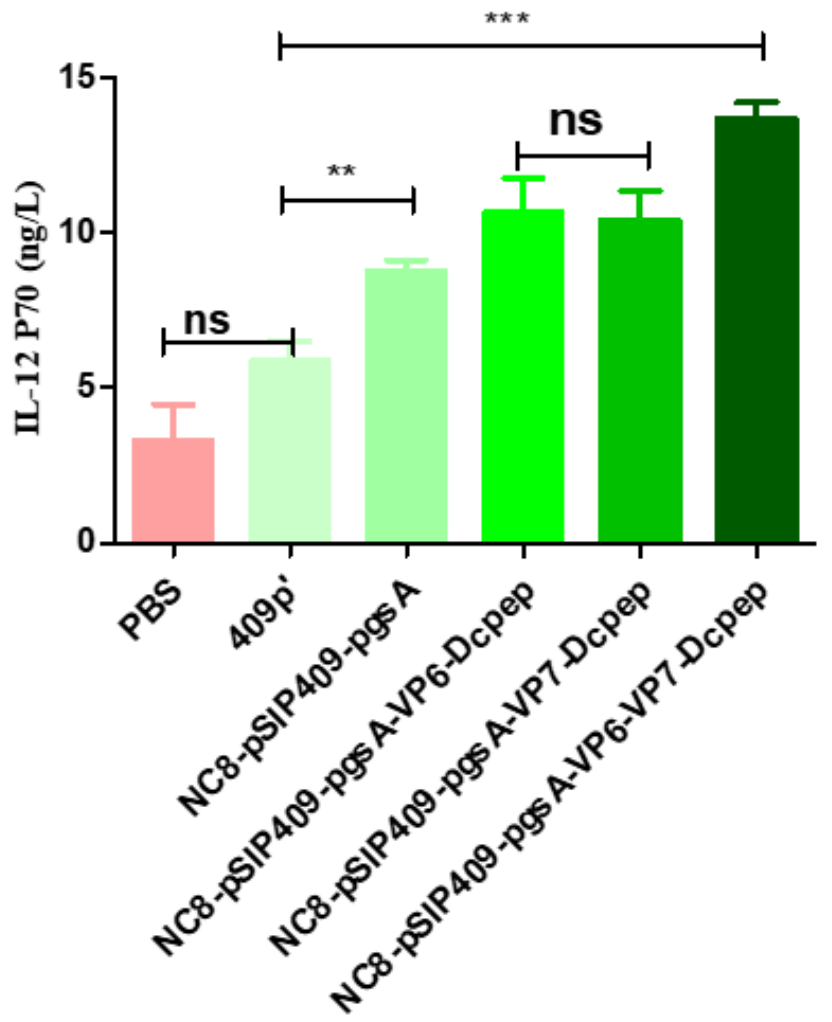

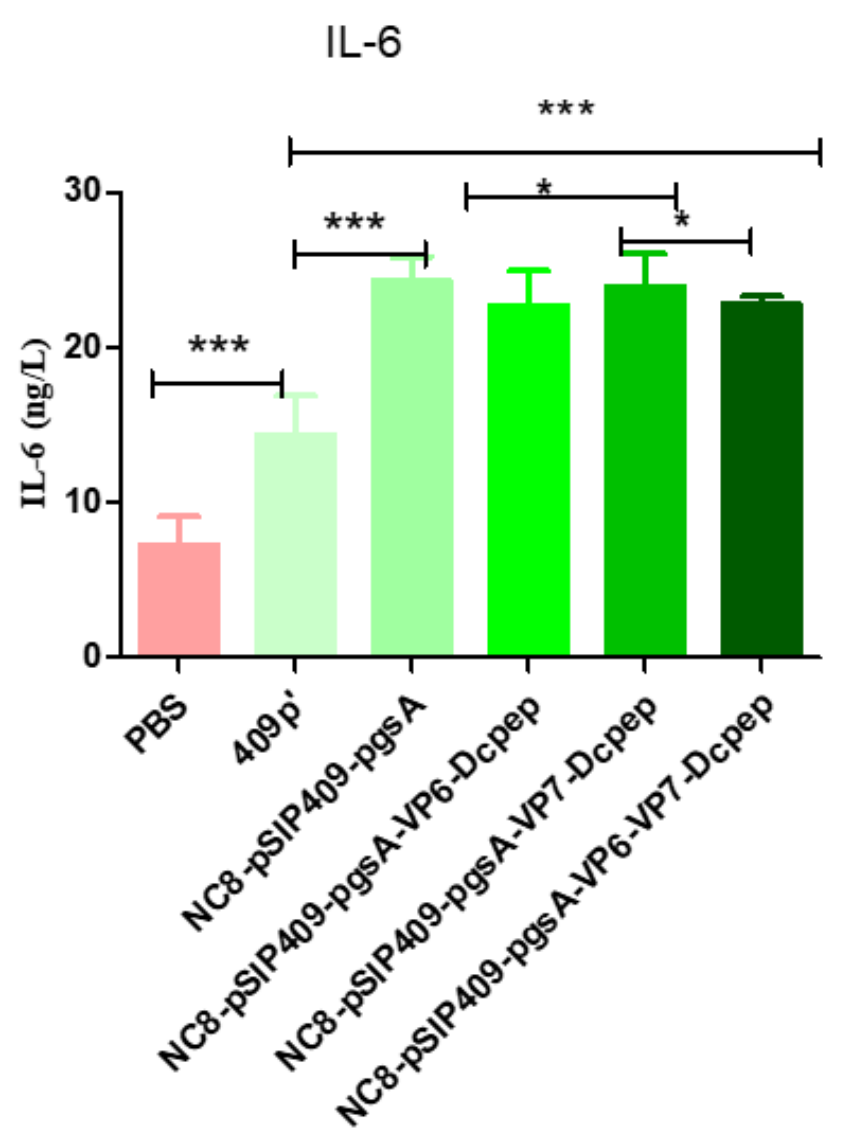

Figure 5

the effect on BMDCs secreting IL-12P70 and IL-6 
PBS

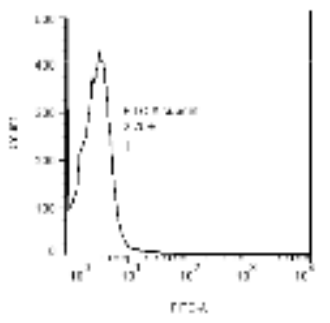

$409 p$

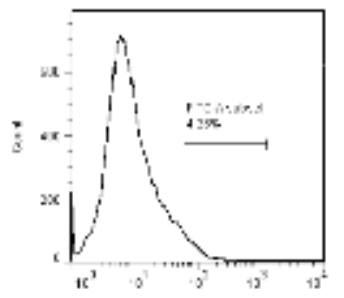

NC8-pSIP409-pgsA

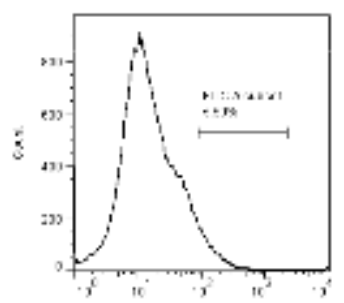

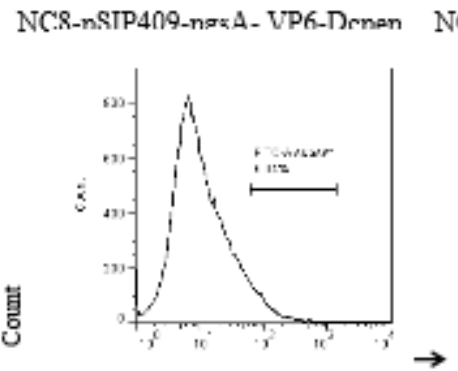

IFN- $\gamma-\mathrm{PE}$
NC8-nSTP409-ngsA- VP7-Drnan

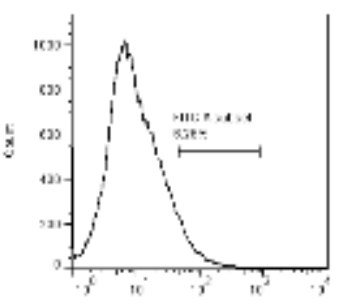

NC8-vSIP409-vasA-VP6-VP7-Dcvep

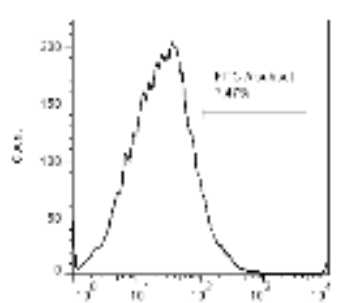

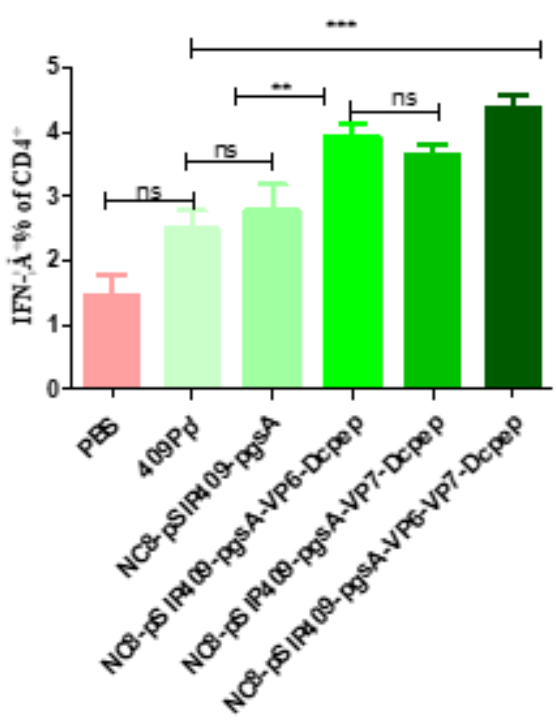

Figure 6

The expression of intracellular IFN- $\gamma+$ after the interaction sorting CD4+ T cells and BMDCs 

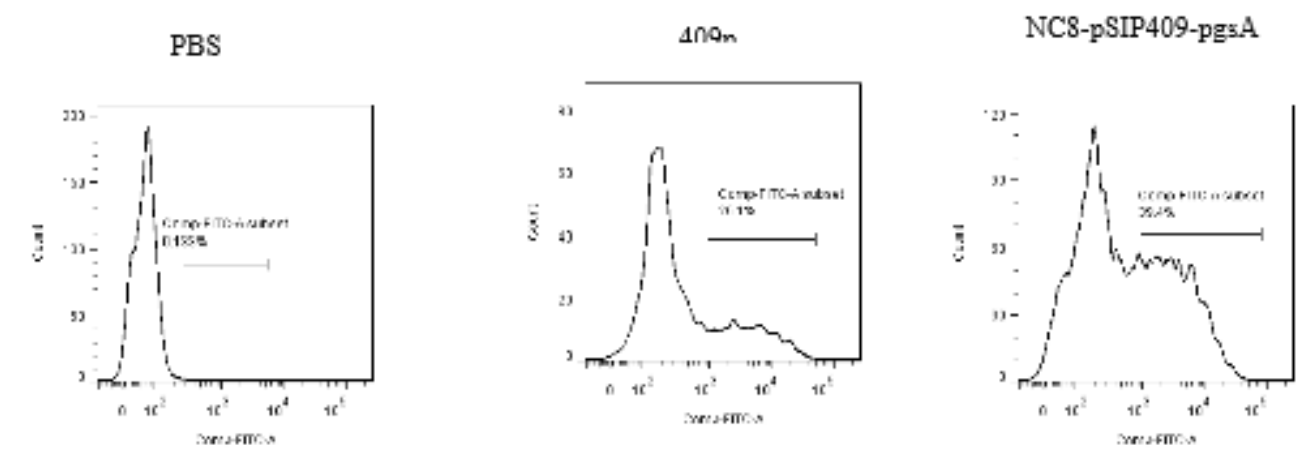

NC8-pSIP409-pgsA-VP6-Dcpep

NC8-pSIP409-pgsA-VP7-Dcpep

NC8-pSIP409-pgsA-VP6-VP7-Dcpep
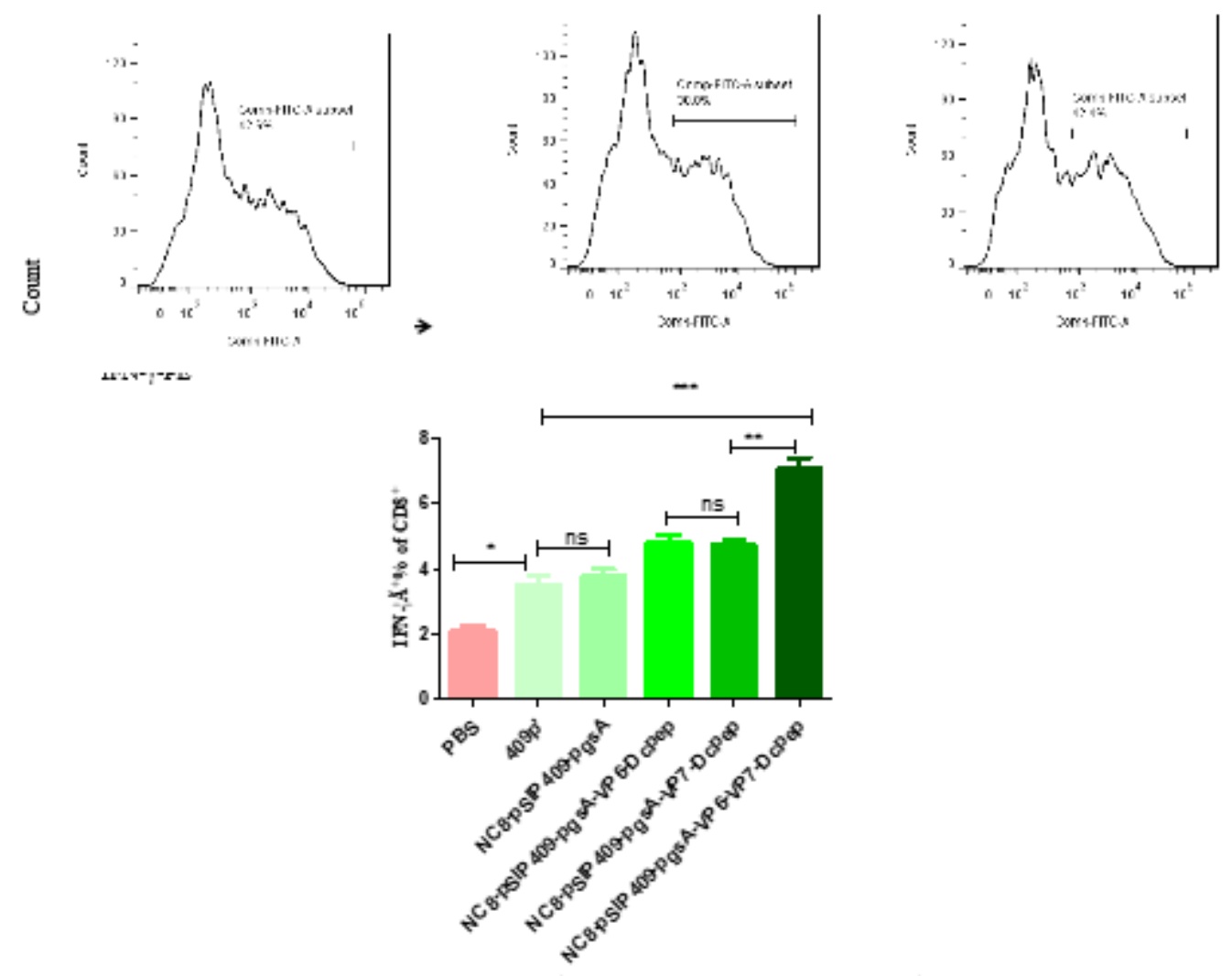

Figure 7

the expression of intracellular IFN- $\mathrm{\gamma}+$ after the interaction sorting CD8+ T cells and BMDCs 

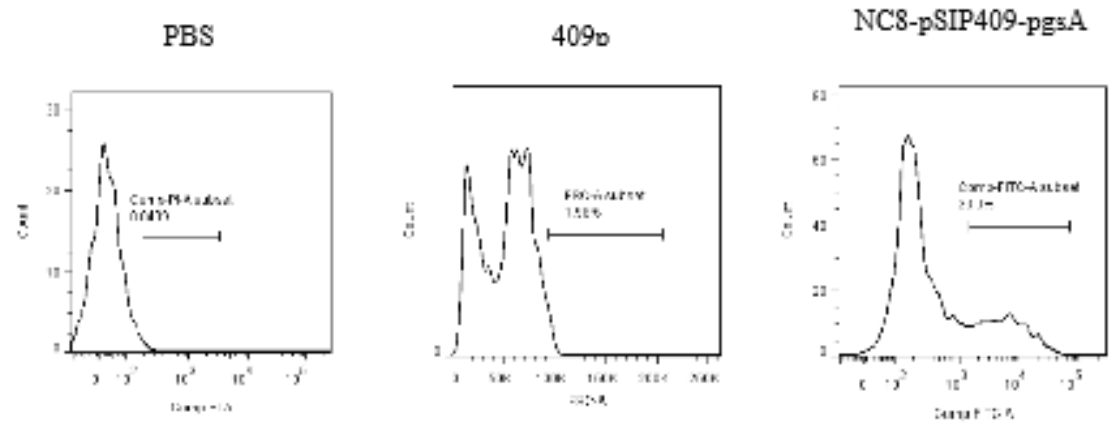

NC8-pSIP409-pgsA-VP6-Dcpep NC8-pSIP409-pgsA-VP7-Dcpep NC8-pSIP409-vasA-VP6-VP7-Dcveb
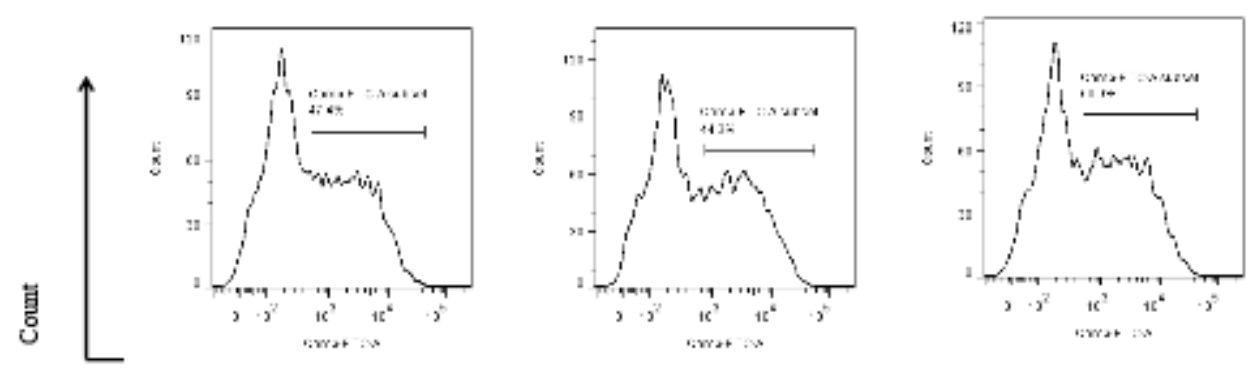

CD107a-PE-CY7

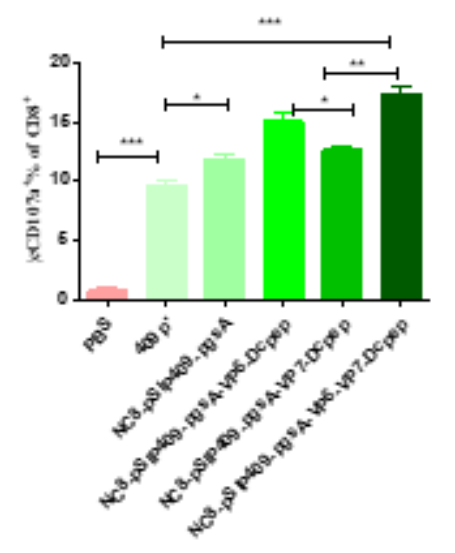

Figure 8

the expression of intracellular CD107a+ after the interaction sorting CD8+ T cells and BMDCs 


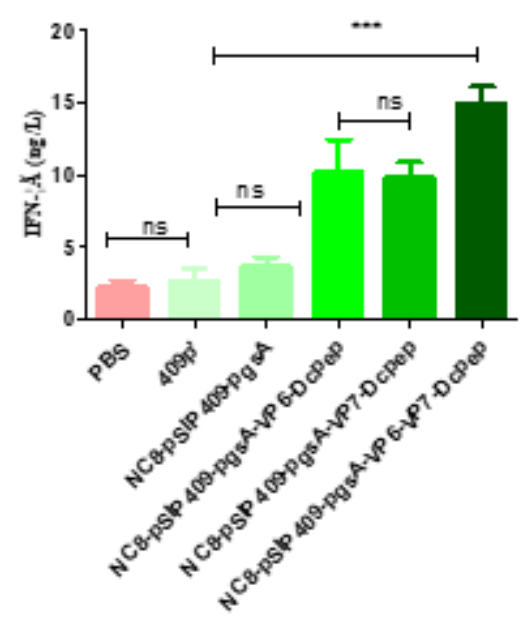

\section{Figure 9}

the content of supernatant IFN- $y$ after CD4+ T cells were co-cultured with BMDCs

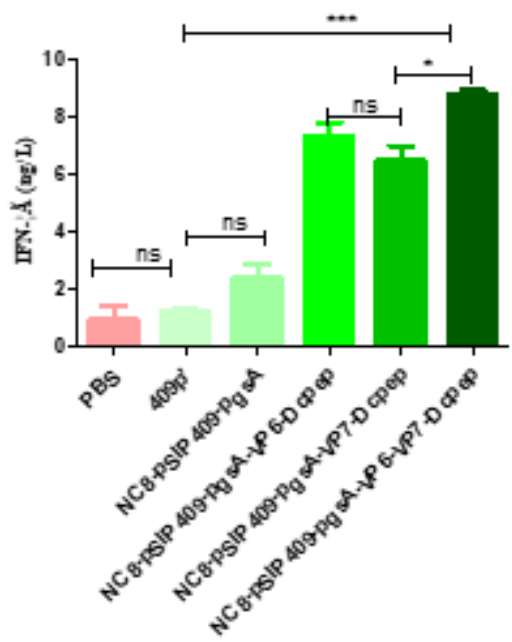

Figure 10

The content of supernatant IFN- $y$ after CD8+ T cells were co-cultured with BMDCs 

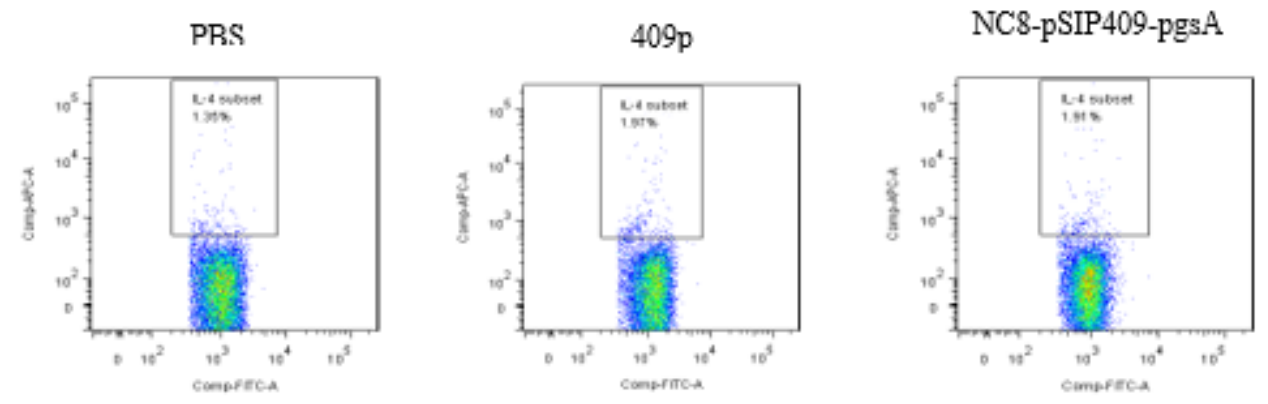

NC8-pSIP409-pgsA- VP6-Dcpep NC8-pSIP409-pgsA-VP7-Dcpep NC8-pSIP409-pgsA-VP6-VP7-Dcpep
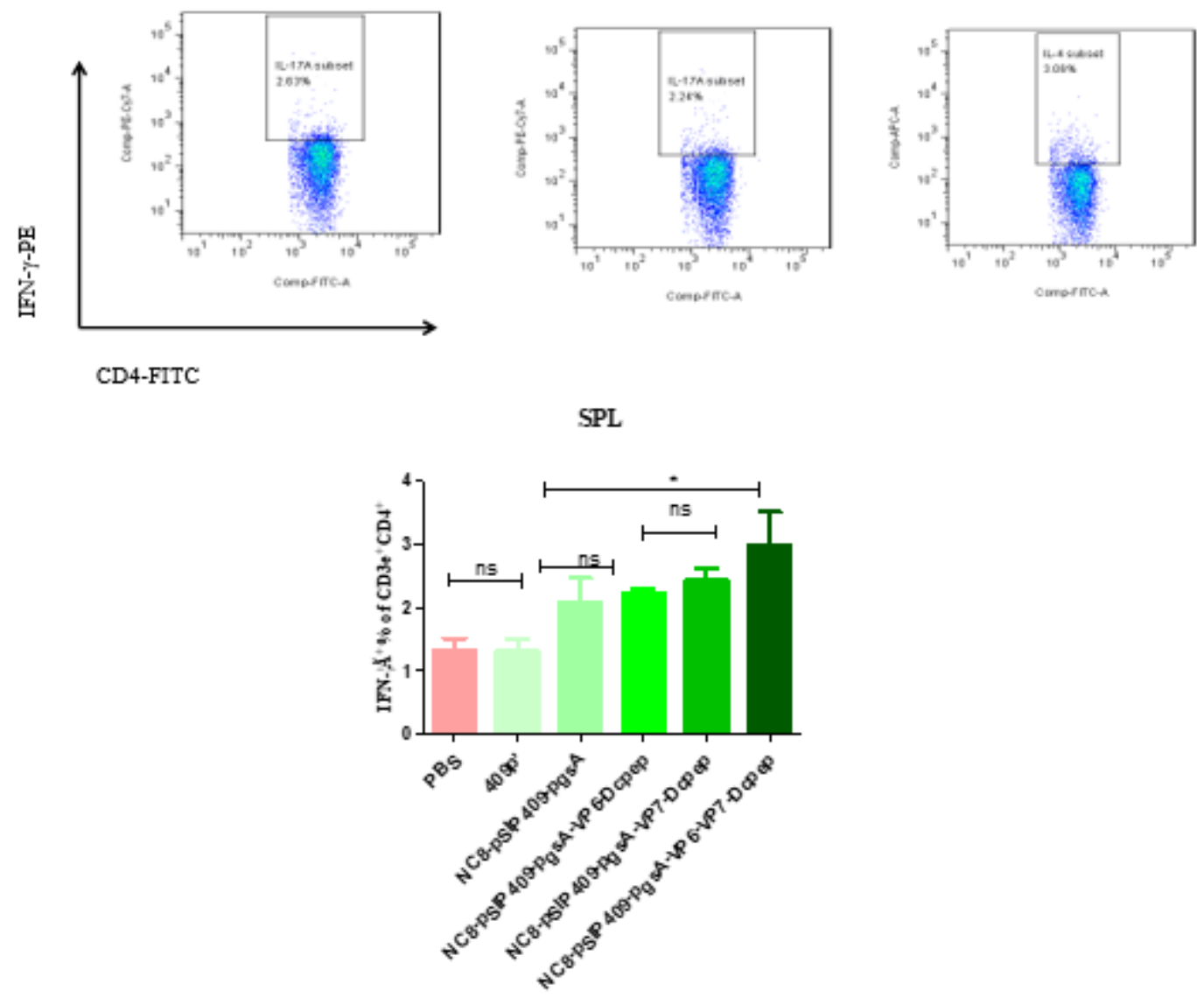

\section{Figure 11}

The percent of CD4+IFN- $\gamma+$ T cells in response to VP6 and VP7 in mouse spleen 

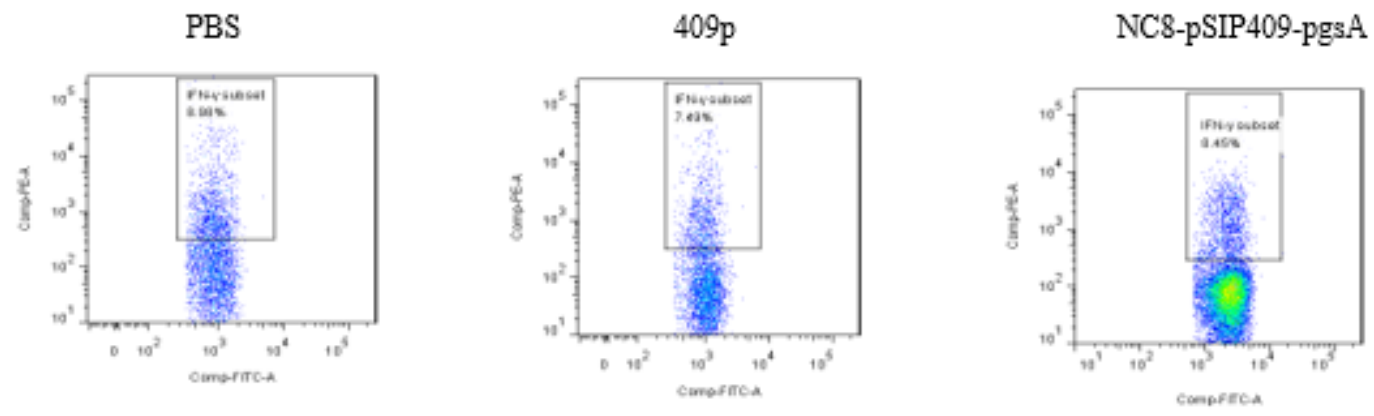

NC8-pSIP409-pgsA-VP6-Dcpep

NC8-pSIP409-pgsA-VP7-Dcpep NC8-pSIP409-pgsA-VP6-VP7-Dcpep
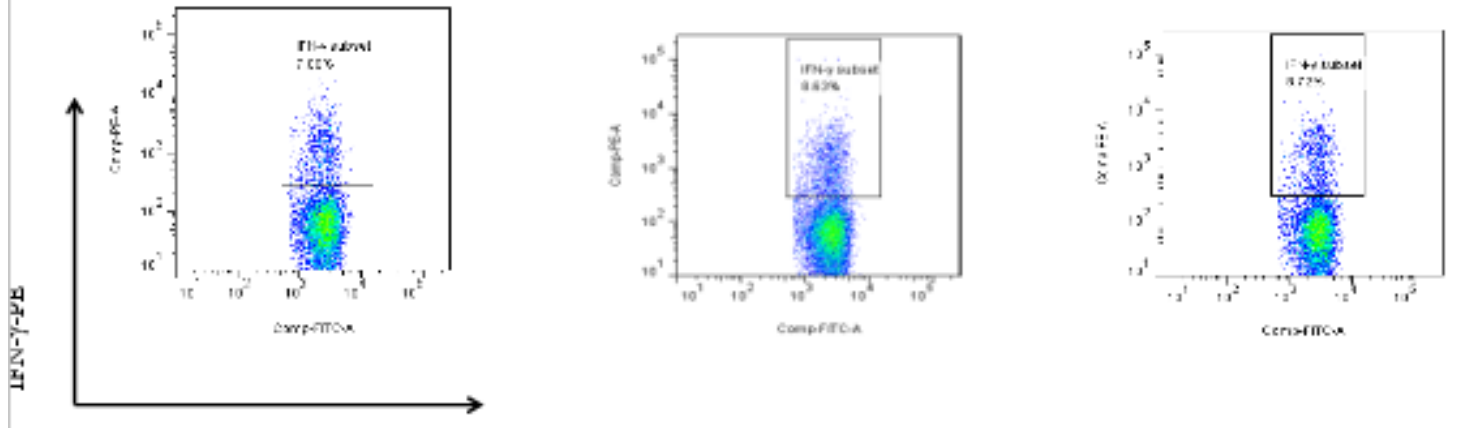

CD4-FITC

\section{MLN}

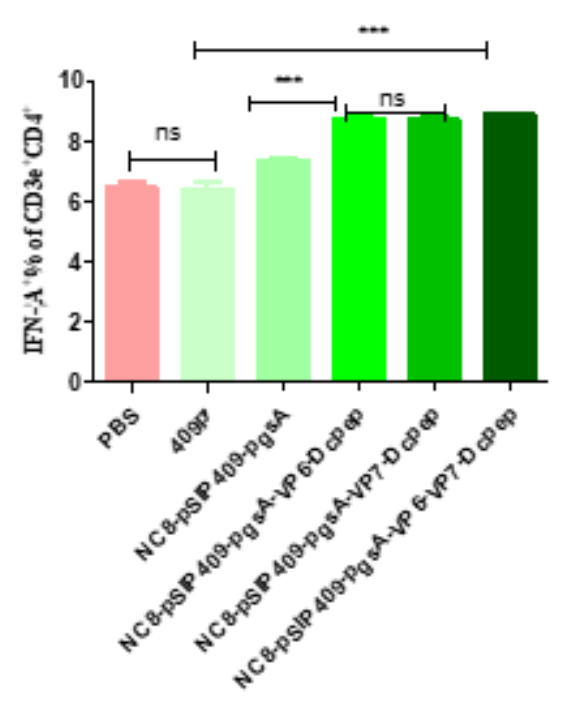

Figure 12

the percent of CD4+IFN- $\gamma+T$ cells in response to VP6 and VP7 in mouse MLN 

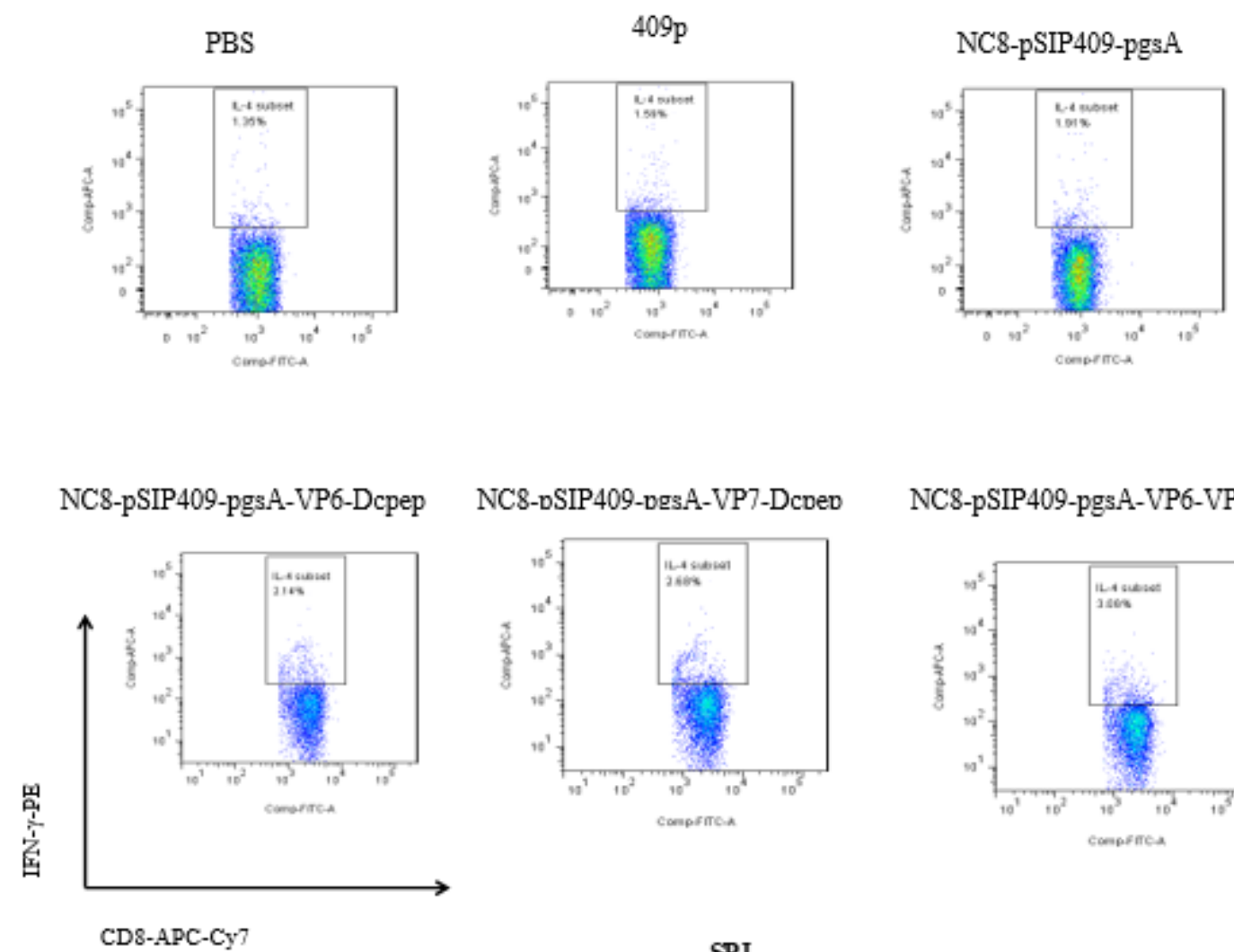

NC8-pSIP409-pgsA-VP7-Dcped

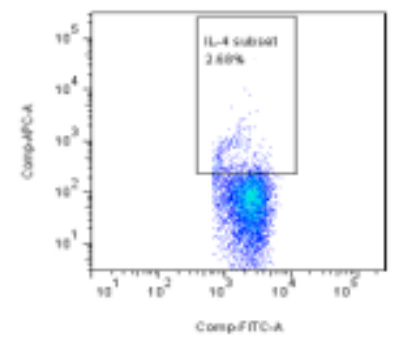

NC8-pSIP409-pgsA-VP6-VP7-Dcpep

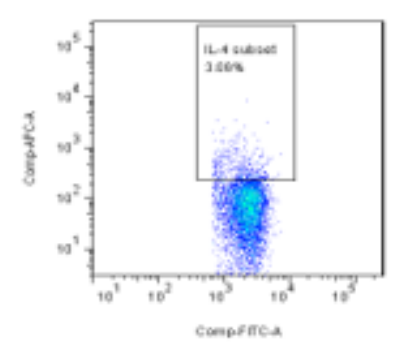

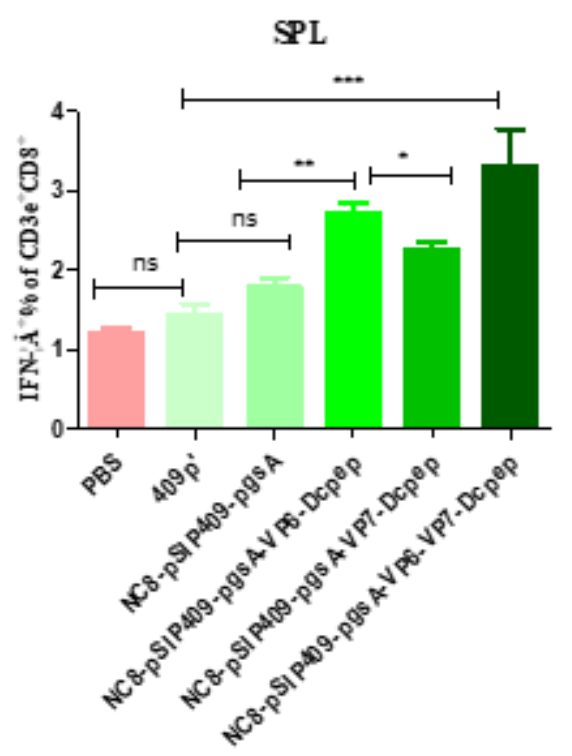

Figure 13

the percent of CD8+IFN- $\gamma+$ T cells in response to VP6 and VP7 in mouse spleen 


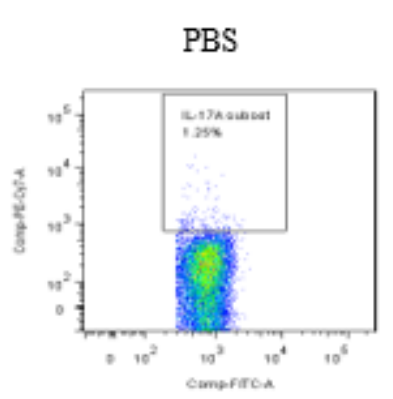

NC8-pSIP409-pgsA-VP6-Dcpep

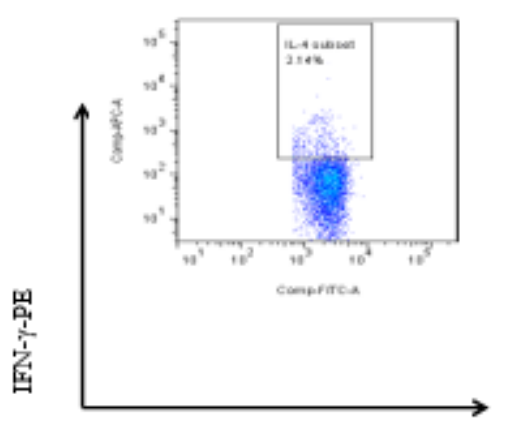

CD8-APC-Cy7

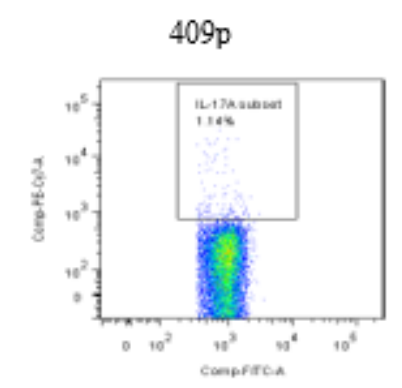

NC8-pSIP409-pgsA-VP7-Dcpep

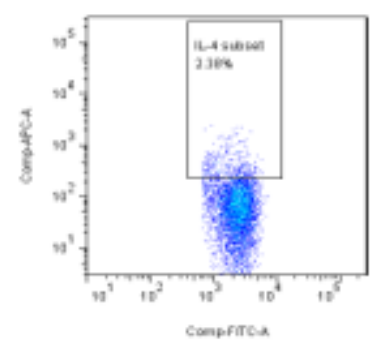

NC8-pSIP409-pgsA-VP6-VP7-Dcpep

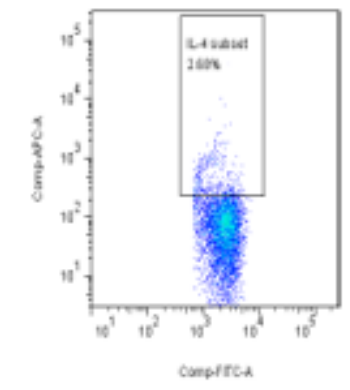
NC8-pSIP409-pgsA

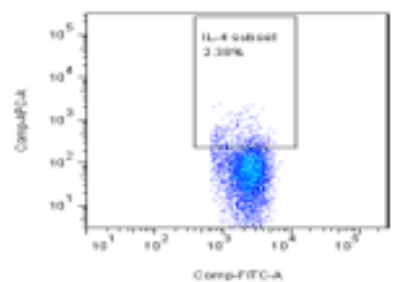

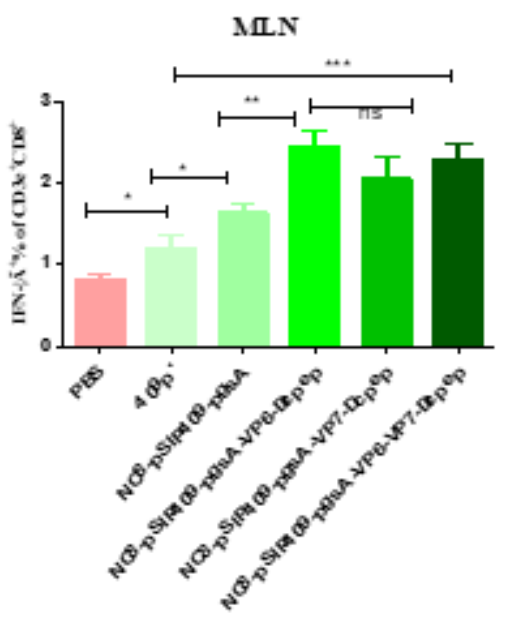

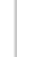



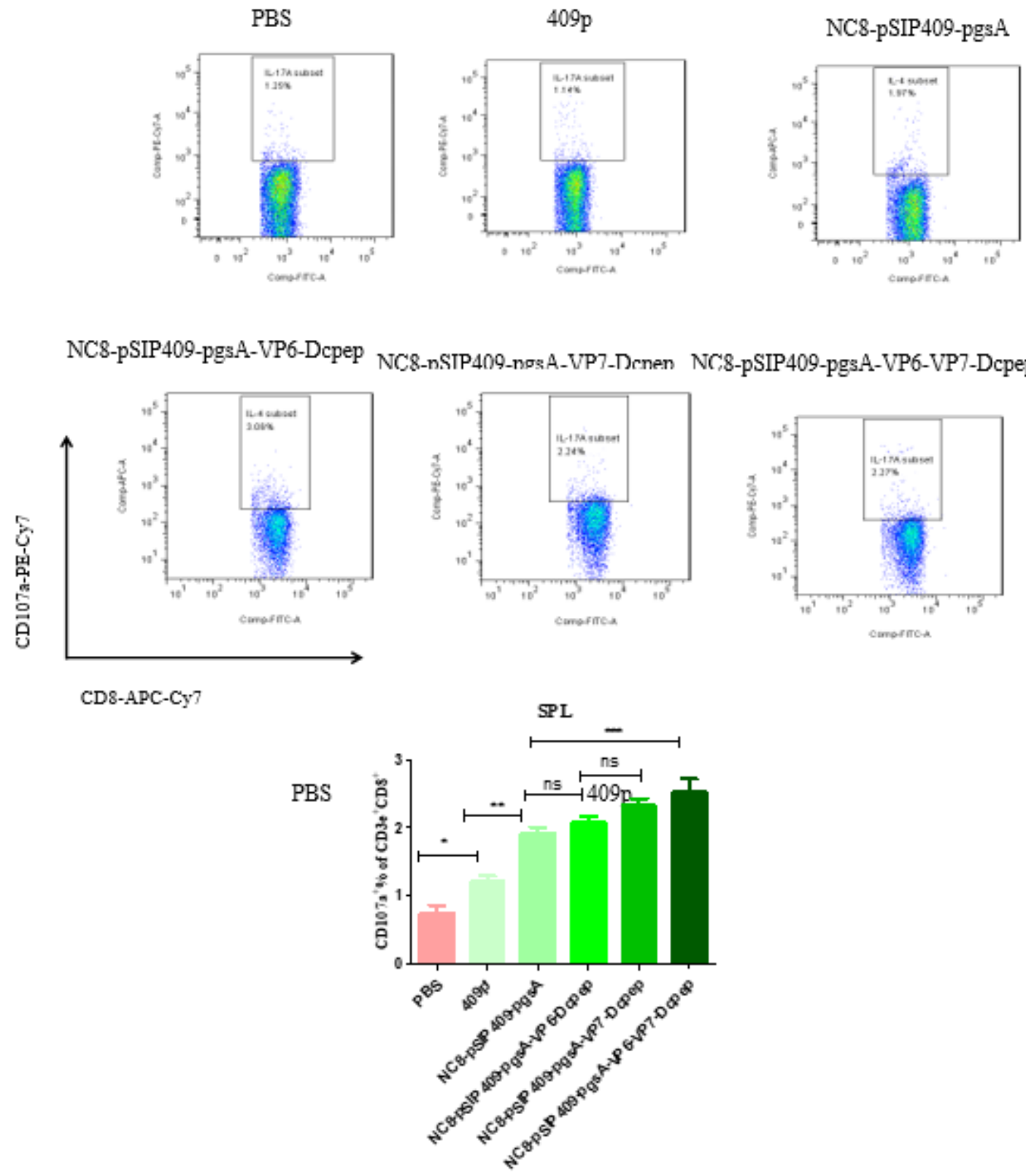

Figure 15

the percent of CD8+CD107a+ T cells in response to VP6 and VP7 in mouse spleen 
PBS

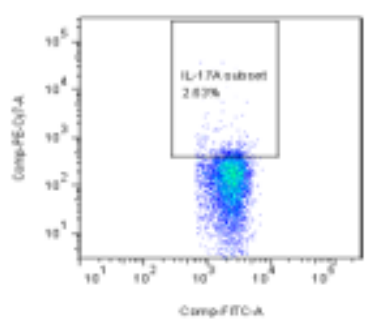

$409 \mathrm{p}$

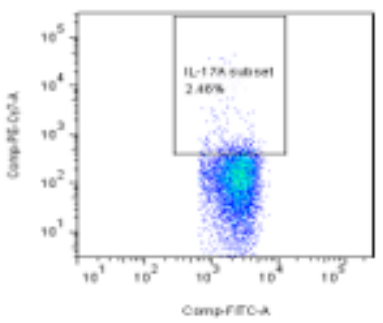

NC8-pSIP409-pgs.A

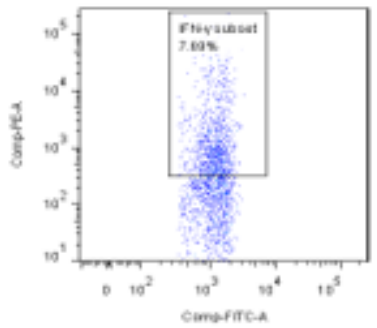

NC8-pSIP409-pgsA-VP6-Dcpep NC8-pSIP409-pgsA-VP7-Dcpep NC8-pSIP409-pgsA-VP6-VP7-Dcpep
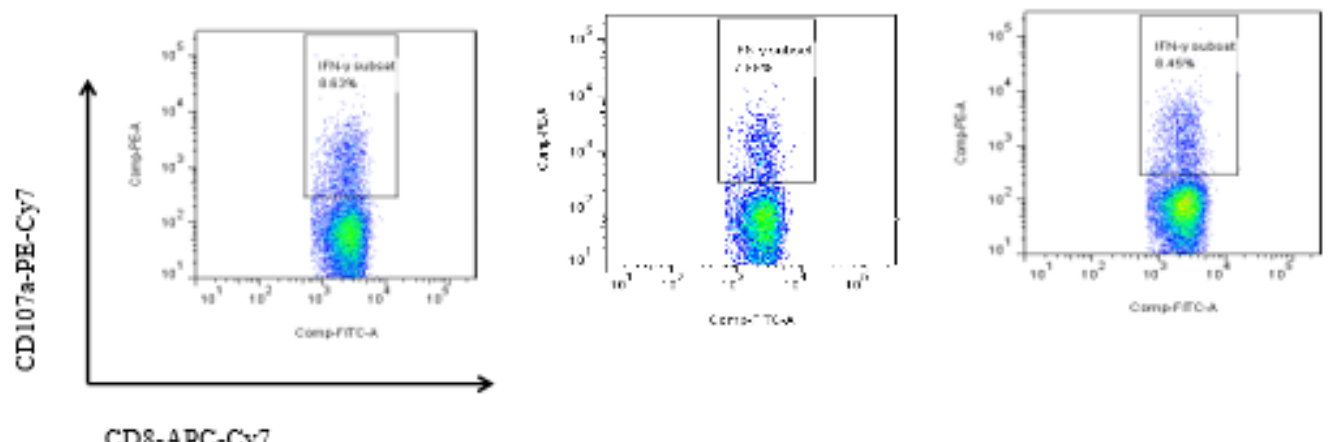

CD8-APC-Cy7

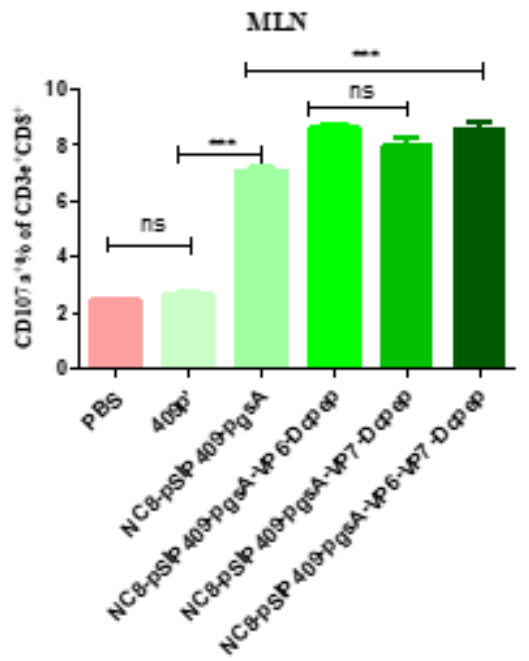

Figure 16

the percent of CD8+CD107a+ T cells in response to VP6 and VP7 in mouse MLN 

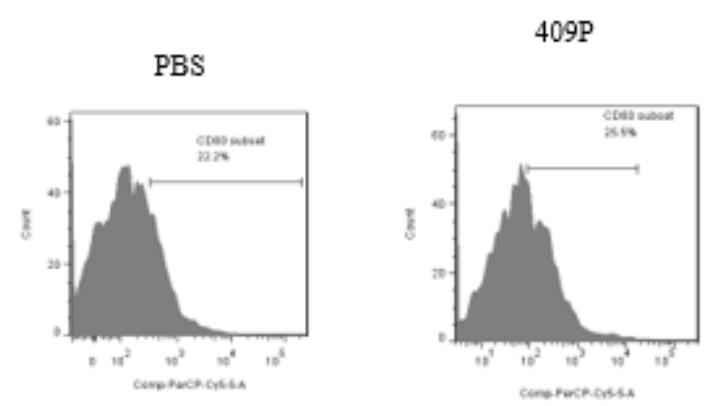

NC8-pSIP409-pgsA

NC8-pSIP409-pgsA-VP6-Dcpep NC8-pSIP409-pgsA-VP7-Dcpep

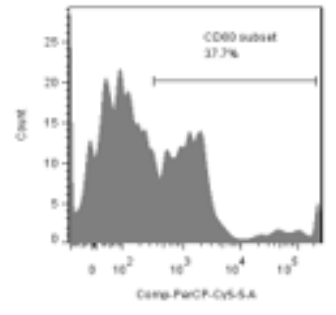

NC8-pSIP409-pgaA-VP6-VP7-Dcpep
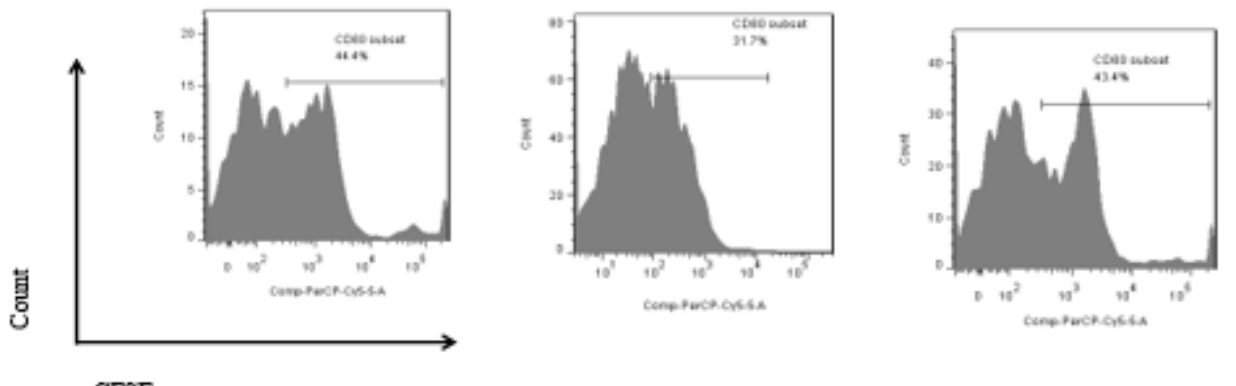

CFSE

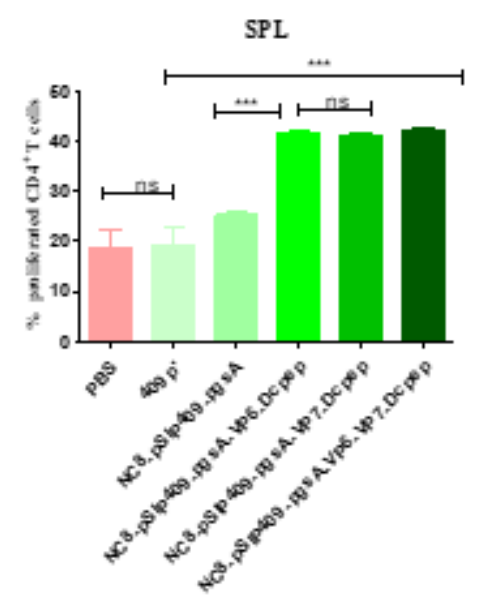

Figure 17

the result of $\mathrm{CD} 4+$ proliferating $\mathrm{T}$ cells in mouse spleen 

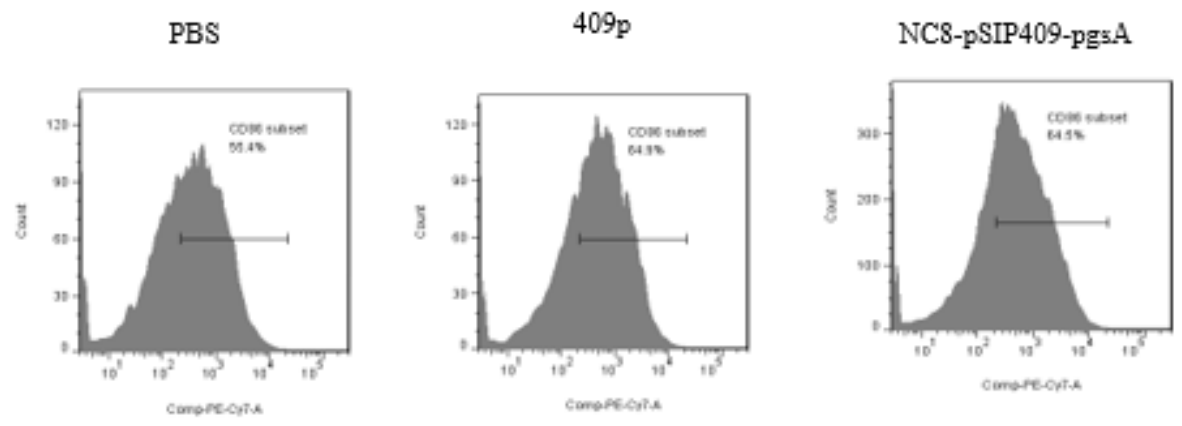

NC8-pSIP409-pgsA-VP6-Dcpep

NC8-pSIP409-pgsA-VP7-Dcpep

NC8-pSIP409-pgsA-VP6-VP7-Dcpep
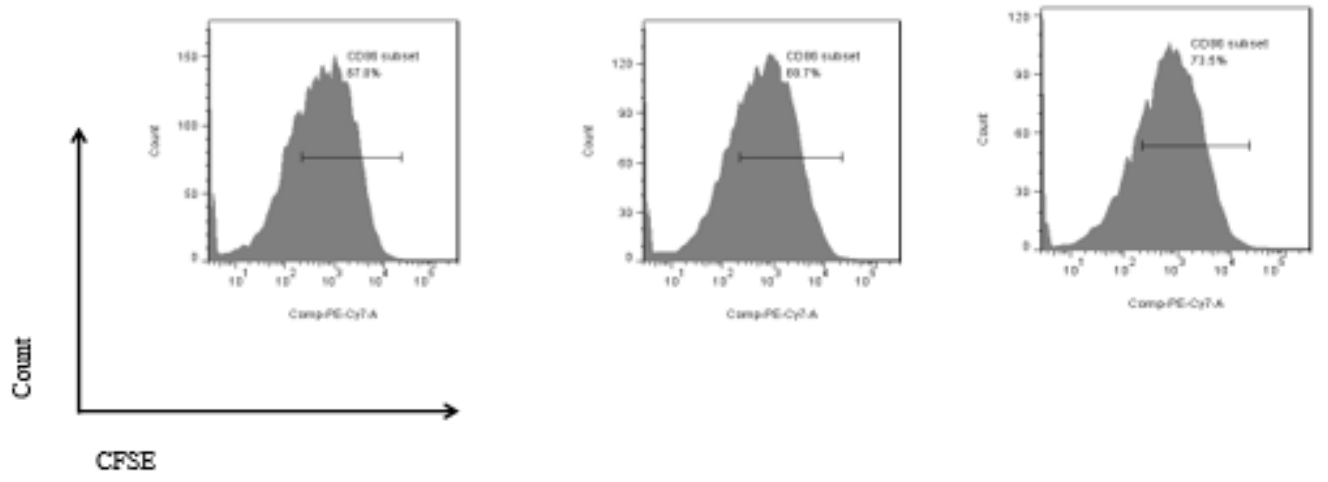

CFSE

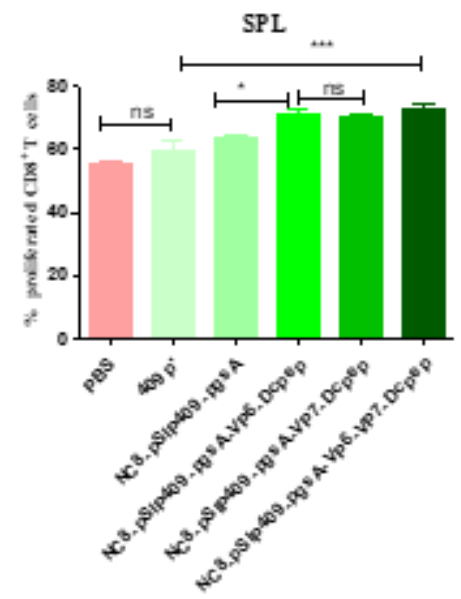

Figure 18

the result of CD8+ proliferating $T$ cells in mouse spleen 